\title{
Characterization of the Circuits That Generate Spontaneous Episodes of Activity in the Early Embryonic Mouse Spinal Cord
}

\author{
M. Gartz Hanson and Lynn T. Landmesser \\ Department of Neurosciences, Case Western Reserve University, School of Medicine, Cleveland, Ohio 44106-4975
}

In the developing nervous system, patterned spontaneous activity affects a variety of developmental processes. Thus, it is important to identify the earliest time that such activity occurs and to characterize the underlying circuitry. In isolated mouse spinal cord-limb preparations, highly rhythmic spontaneous activity occurred as early as embryonic day 11 (E11)-E12, when many lumbosacral motoneurons were still migrating and extending their peripheral projections. This activity required both electrical and chemical transmission, and acetylcholine, rather than glutamate, provided the main excitatory drive. Our data are consistent with motoneurons themselves playing a critical role in generating such activity by making excitatory connections on each other and on GABAergic interneurons via dihydro$\beta$-erythroidine hydrobromide $(\mathrm{DH} \beta \mathrm{E})$-insensitive nicotinic receptors. This resulted in the generation of local bursts. Consistent with these observations, E12-E12.5 mouse motoneurons retrogradely labeled by HRP were observed to have extensive axon collaterals that projected locally within the lateral motor column and to interneuron-containing regions dorsal and medial of the lateral motor column. Cholinergic axons, presumably from motoneurons, were also observed in the ventral and lateral funiculi. However, for local bursts to propagate throughout the cord, a second $\mathrm{DH} \beta \mathrm{E}$-sensitive cholinergic pathway that also involved glycinergic interneurons was required. This circuit characterization should facilitate the use of genetic mutations that alter specific subpopulations of interneurons or cholinergic transmission to determine how modifying different aspects of this early activity affects subsequent development of the spinal motor circuit.

Key words: motoneuron; interneuron; motor; cholinergic; glycinergic; GABAergic; gap junctions; development

\section{Introduction}

Rhythmic spontaneous episodes of activity are widespread in the developing vertebrate CNS, occurring in regions involved in the generation of motor patterns, the processing of visual information, and learning and memory (Hamburger et al., 1965; Meister et al., 1991; Katz and Shatz, 1996; Chub and O'Donovan, 1998; Garaschuk et al., 1998; Kandler and Katz, 1998; Milner and Landmesser, 1999) (for review, see Feller, 1999; O’Donovan, 1999). In the developing visual system, spontaneous episodes of activity are important in the formation and refinement of neuronal circuits, including axonal segregation into specific layers in the lateral geniculate nucleus (Shatz, 1996; Penn et al., 1998; Stellwagen and Shatz, 2002) and in the organization of the visual cortex (Weliky and Katz, 1999). Within the ferret eye, spontaneous activity propagates across distinct domains of the retina as waves (Wong et al., 1993, 1995; Feller et al., 1996, 1997). Early in retina development [postnatal day 0 (P0)-P9 ferret and embryonic day 8 (E8)-E11 chick], acetylcholine (ACh) provides the excitatory drive for these waves (Feller et al., 1996; Catsicas et al., 1998; Penn et al., 1998) through complex interactions between amacrine cells and retinal ganglion cells (Zhou, 1998). As the retina develops (E13-

Received July 24, 2002; revised 0ct. 4, 2002; accepted 0ct. 15, 2002.

This work was supported by National Institutes of Health National Institute of Neurological Disorders and Stroke Grants NS-19640 and NS-23678. We thank L. Polo-Parada, C. Bose, and N. llic for helpful suggestions with both the experiments and this manuscript and B. Strowbridge and S. Herlitze for comments on this manuscript.

Correspondence should be addressed to Dr. Lynn Landmesser, Department of Neurosciences, Case Western Reserve University, 10900 Euclid Avenue, Cleveland, OH 44106-4975. E-mail: It|@po.cwru.edu.

Copyright $\odot 2003$ Society for Neuroscience $\quad 0270-6474 / 03 / 230587-14 \$ 15.00 / 0$
E18 chick), this excitatory drive switches from ACh to glutamate (Wong, 1999; Sernagor et al., 2000).

Excitatory spontaneous activity may play similar roles in the development of the spinal motor circuit. For instance, in the early chick spinal cord (E4-E5), at a stage of development when axons are still growing to their targets, cord circuits generate highly rhythmic episodes of spontaneous activity, and cholinergic and GABAergic inputs have been shown to modulate the rhythm and pattern of these episodes (Milner and Landmesser, 1999). At later stages (E9), well after target innervation and the formation of the neuromuscular junction (Chub and O'Donovan, 1998; Usiak and Landmesser, 1999), glutamatergic and GABAergic interneurons provide much of the excitatory drive for spontaneous bursting (Sernagor et al., 1995; Chub and O'Donovan, 1998). However, the motoneurons themselves could also contribute to spontaneous episodes of activity by activating interneurons via their axon collaterals. In fact in the E10-E12 chick, cholinergic collaterals have been shown to activate a Renshaw-like group of interneurons that may be responsible for subsequently activating cells throughout the circuit (Wenner and O'Donovan, 1999, 2001). Consistent with this idea, motoneurons appeared to depolarize slightly before the interneurons in this E10 circuit; however, pharmacological blockade of transmission from the collaterals to the Renshaw-like interneurons did not block spontaneous bursting (Ritter et al., 1999). Thus in the E10 chick, motoneurons may normally contribute to but are not required for the synaptic drive that generates spontaneous episodes.

In the E12 mouse spinal motor circuit, a stage when motoneu- 
rons are still growing to their peripheral targets (Jones, 1979), we show that cholinergic, glycinergic, and GABAergic input, rather than glutamate, drive the circuit and that all are excitatory. We further show that motoneurons via nicotinic transmission play a critical role in generating spontaneous activity with participating GABAergic interneurons by initiating localized bursting episodes. However, for such episodes to propagate throughout the cord, an additional circuit that uses cholinergic and glycinergic as well as electrical transmission is required.

\section{Materials and Methods}

In vitro spinal cord-hindlimb preparation. This protocol is a modification of the chicken in vitro spinal cord-hindlimb preparation described previously (Landmesser and O'Donovan, 1984). C57BL/J6 mouse embryos between the ages of E11.5 and E13 or stage 25 chick embryos were decapitated, eviscerated, and placed in cool oxygenated Tyrode's solution. A ventral laminectomy was performed to expose the spinal cord and allow oxygenation. Careful removal of the skin and surrounding limb connective tissue with fine tungsten needles exposed motor nerve trunks. After dissection, the Tyrode's solution was warmed to $30^{\circ} \mathrm{C}$ for the duration of the experiment. Nerve recordings were performed using extra fine-tip suction electrodes pulled from polyethylene tubing (PE-190; Clay Adams, Parsippany, NJ). A continuous negative pressure was used to draw the tips of growing muscle nerves into the electrode, producing a tight seal (Fig. $1 \mathrm{~A}$ ). Activity was recorded continuously either on an analog tape recorder (Vetter, Rebersburg, PA) with subsequent digital conversion and storage on the computer or directly on the computer with Axoscope 8 (Axon Instruments, Foster City, CA). It was simultaneously displayed on an oscilloscope (R5030; Tektronix, Beaverton, OR) and chart recorder (Gould Inc, Cleveland, $\mathrm{OH}$ ). To produce an episode of activity, spinal cords were stimulated with suction electrodes at different sites (see Fig. $1 \mathrm{~A}$ ) with a Grass (Quincy, MA) S48 stimulator that was isolated from ground with a stimulator isolation unit (Grass PSIU6B).

Drug treatments. Neurochemicals and receptor blockers were bathapplied to the in vitro spinal cord-hindlimb preparation using a pump that circulated oxygenated Tyrode's solution over the preparation. Each drug was evaluated either alone or in combination with other drugs for its effect on spontaneous bursting activity. Drugs were applied for a minimum of 20 min before assessing their effectiveness on spontaneous activity by quantifying the change in episode frequency, number of bursts per episode, and burst structure; however, in many cases, effects of the drugs were immediately evident. As shown in Figure $1 B$, episodes of bursting activity, which consisted of one or more closely spaced bursts (within seconds of each other), occurred at regular intervals of $\geq 1 \mathrm{~min}$. This interepisode interval was used to quantify the frequency of episodes. The interepisode interval was defined as the time between the end of one episode and the beginning of the next. When comparing different drug treatments, $\geq 10$ episodes were measured, and the data were displayed as mean \pm SE. Except where indicated, a given drug treatment was performed on two or more embryos with similar results, and, in most cases, drugs were washed out until burst parameters returned to control values (several minutes to 1-2 hr depending on the drug). Significance of data was evaluated by Student's $t$ test, which determined the $p$ value (SigmaPlot 2.0; Jandel Scientific, Corte Madera, CA); $p<0.05$ was considered significant.

A list of the drugs used includes the following: cholinergic receptor blockers d-tubocurarine (dTC), atropine, dihydro- $\beta$-erythroidine hydrobromide (DH $\beta \mathrm{E})$, mecamylamine, and methyllycoconitine (MLA); cholinergic agonist nicotine; GABA receptor blockers bicuculline and phaclofen; GABA agonist GABA; glutamate receptor blockers APV and CNQX; glutamate agonists glutamate and kainate; Gly receptor antagonist strychnine; and gap junction blocker carbenoxolone. The effects of low-calcium $(0.2 \mathrm{~mm})$, high-magnesium $(7 \mathrm{~mm})$ Tyrode's solution or normal calcium (2 mM), high-magnesium (12 mM) Tyrode's solution were tested to determine the contribution of synaptic input on spontaneous activity.

HRP back-labeling of motoneurons. E12.5 mouse spinal cords were prepared as described above for physiological recordings. Motor roots were injected with $10 \%$ horseradish peroxidase and incubated for $6 \mathrm{hr}$ at $30^{\circ} \mathrm{C}$ in oxygenated Tyrode's solution to allow for retrograde transport to motoneurons. The embryos were fixed in $2 \%$ glutaraldehyde overnight and then washed with PBS. The tissue was embedded in agarose and sectioned at $50 \mu \mathrm{m}$ using a vibratome (OTS 3000; Electron Microscope Sciences). The sections were incubated with DAB $(0.5 \mathrm{mg} / \mathrm{ml})$ in Tris buffer containing $0.03 \%$ hydrogen peroxide for $45 \mathrm{~min}$, dehydrated using a series of ethanol washes (70,90, and 100\%), cleared in xylene, and then mounted between two coverslips in Permount.

Immunohistochemistry. Embryonic day 12.5 mouse embryos were prepared as stated above. The embryos were then fixed in $3.7 \%$ formaldehyde for $1 \mathrm{hr}$ at room temperature. The embryos were washed in 5\% sucrose and PBS for $1 \mathrm{hr}$, placed in 30\% sucrose and PBS overnight at $4^{\circ} \mathrm{C}$, placed in a $1: 1$ mixture of $60 \%$ sucrose and tissue-freezing medium (Triangle Biomedical Sciences, Durham, NC), and frozen in dry icecooled isopentane, before cryostat sectioning at $18 \mu \mathrm{m}$ at $-30^{\circ} \mathrm{C}$ (Cryocut 1800; Leica, Nussloch, Germany). The sections were incubated with antibodies against the vesicular acetylcholine transporter (antiVCAT; V5387; Sigma, St. Louis, MO) and in some cases colabeled with antibodies against choline acetyltransferase (anti-ChAT; AB1448; Chemicon, Temecula, CA) to identify cholinergic neurons for $1 \mathrm{hr}$ sequentially, incubated with Alexa-488 secondary antibody (Molecular Probes, Eugene, OR) and biotin-conjugated secondary antibody plus avidin-rhodamine (Vector Laboratories, Burlingame, CA), respectively, and then rinsed and mounted using a ProLong Antifade kit (Molecular Probes).

Image acquisition. Imaging was performed with a digital camera (Olympus MagnaFire) using the MagnaFire 2.0 software. For HRPlabeled motoneurons, neurites from particular motoneurons were first identified using a differential interference contrast condenser on an inverted microscope (Nikon Diaphot 300). Images were captured at several different focal planes (upright microscope, $63 \times$ oil, Nikon MicrophotFX). The images were then overlaid and merged in the $z$-axis using ImagePro Plus software (MediaCybernetics, Silver Spring, MD).

\section{Results}

Before and during innervation of peripheral targets, rhythmic spontaneous activity in the mouse spinal cord is mediated by electrical and chemical transmission

Although rhythmic spontaneous activity has been characterized in the early embryonic chicken spinal motor circuit (E4-E5; Milner and Landmesser, 1999), less data are available for the corresponding developmental stages in the mouse (Branchereau et al., 2002). To characterize the rhythmic episodes of activity between E11 and E14 in the mouse, during which time motoneurons are growing to and innervating their targets (Jones, 1979), tightfitting suction electrodes were attached to motor nerves in an in vitro spinal cord-hindlimb preparation (Fig. 1A) (for additional methods, see Landmesser and O'Donovan 1984; O'Donovan and Landmesser, 1987). These episodes of activity were highly rhythmic, with little variation in the interepisode intervals at a given developmental stage (Fig. $1 B, C$ ). However, both the duration of the bursting episode (data not shown but previously described by Branchereau et al., 2000) and interepisode intervals increased as the circuit matured (Fig. 1C). Two types of spontaneous episodes were observed. Major episodes propagated throughout the cord, with both right and left sciatic nerves (data not shown) and sciatic and crural trunks (Fig. 1D) bursting approximately in-phase and are therefore defined as propagating episodes. Although infrequent ( 19 of 378 intervals), other episodes were confined to local regions of the spinal cord. For example, the episode from the crural trunk (Fig. 1D, top trace, bracket) was not observed in the ipsilateral sciatic recording (bottom trace). Therefore, we defined these as episodes that were confined to the recorded nerve as local. Finally, unitary spikes occurred at a low frequency through- 


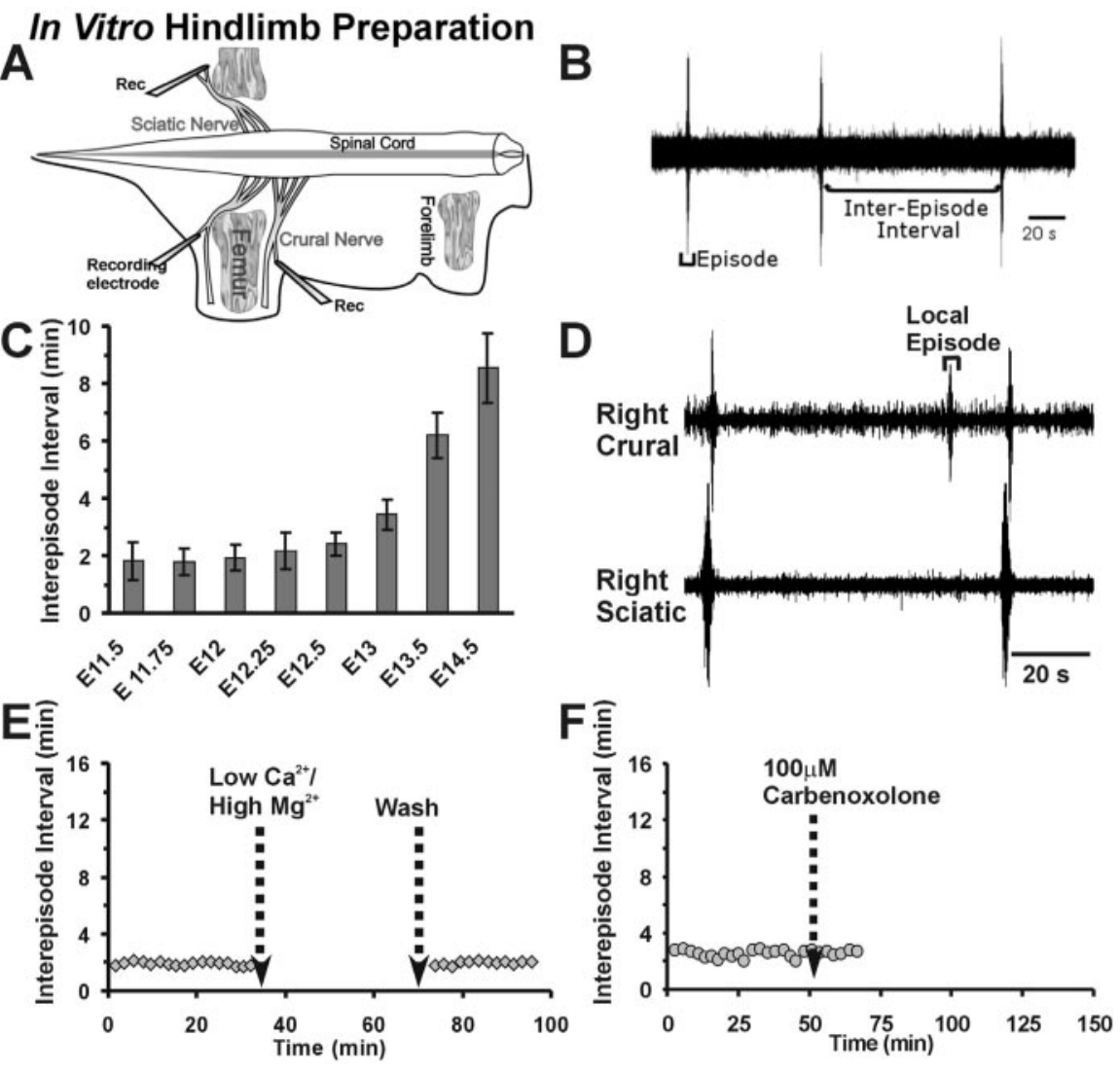

Figure 1. Characterization of spontaneous episodes of activity in the early developing mouse spinal motor circuit. $A$, Suction electrodes were placed on embryonic mouse motor nerves in an isolated spinal cord-hindlimb preparation. B, Spontaneous activity consisted of high-amplitude bursting episodes separated by interepisode intervals of several minutes. Interepisode intervals were very constant for each age but increased with the developmental stage examined ( $C$; mean $\pm S E)$. D, Recordings from different nerves demonstrated that episodes throughout the lumbar spinal cord were generally in-phase. Rhythmic activity could be abolished when chemical transmission was blocked by high $\mathrm{Mg}^{2+}$ and low $\mathrm{Ca}^{2+}(7.0$ and $0.2 \mathrm{~mm} ; E)$ or when electrical transmission was blocked by the gap junction inhibitor carbenoxolone $(100 \mu \mathrm{m} ; F)$.

out the intervals (Fig. $1 D$ ), although they tended to increase (data not shown) as the time of a bursting episode approached. This has also been observed in E10 chick cord (Chub and O'Donovan, 2001), where this has been attributed to the recovery of the circuit from depression caused by the preceding episode.

Both electrical coupling and chemical transmission could contribute to the depolarization of motoneurons that produces these early rhythmic episodes of activity. To evaluate the importance of chemical transmission, which is dependent on extracellular $\mathrm{Ca}^{2+}$, the preparation was perfused in the presence of low $\mathrm{Ca}^{2+}(0.2 \mathrm{~mm})$ and high $\mathrm{Mg}^{2+}(7.0 \mathrm{~mm})$. This abolished the rhythmic episodes of activity (Fig. $1 E$ ), consistent with the requirement of chemical transmission for the propagation of spontaneous episodes in the early (E12) mouse spinal cord circuit. It is also possible that lowering the calcium concentrations could affect other processes, such as $\mathrm{Ca}^{2+}$-induced calcium release. This result is similar to that observed in the immature chick spinal motor circuit (E5; Milner and Landmesser, 1999).

Although chemical transmission appeared necessary for rhythmic episodes of activity, electrical coupling between neurons might also contribute to the generation of these episodes. Although gap junction coupling of neurons is found in many regions of the CNS, its function during development is currently not well understood (Roerig and Feller, 2000). Nevertheless, electrical coupling appears capable of synchronizing the bursting activity in embryonic zebrafish spinal cord (Saint-Amant and Drapeau, 2001). To determine whether electrical transmission affected the rhythmic episodes of activity in E12 embryonic mouse cord, carbenoxolone $(100 \mu \mathrm{M})$, a gap junction inhibitor (Draguhn et al., 1998; Nolan et al., 1999), was bath-applied. This abolished the rhythmic episodes within 15 $\min (n=3)$ (Fig. $1 F)$, similar to the observation made in the $\mathrm{E} 5$ chick spinal cord (Milner and Landmesser, 1999). Another gap junction blocker, octanol (3 mM), also abolished activity (data not shown). These observations are consistent with electrical coupling being required to generate spontaneous activity. However, such compounds have also been shown to affect other processes, such as in the inactivation of sodium channels (Elliot and Elliot, 1989). In summary, both gap junction-mediated coupling and chemical transmission appear necessary for the propagation of rhythmic episodes of activity in the early (E12) mouse spinal cord circuit.

\section{Rhythmic spontaneous activity requires cholinergic and glycinergic} transmission but not glutamate

We next characterized the transmitters involved in the generation and propagation of the rhythmic episodes. In the mature spinal motor circuit, the main excitatory drive is from glutamatergic spinal interneurons, whereas inhibition is provided by glycinergic and GABAergic interneurons (Rekling et al., 2000). Therefore, endogenous glutamate, released by interneurons in the E12 mouse motor circuit, could drive circuit activity via NMDA or AMPA/kainate receptors. However, the addition of CNQX, an AMPA/kainate receptor antagonist, APV, an NMDA receptor antagonist, or both had no affect on the rhythmic episodes of activity (Fig. 2A). Similar results were reported recently for the AMPA antagonist kynurenic acid (Branchereau et al., 2002) (for E15 rat, see Nishimaru et al., 1996). These data indicate that in contrast to the more mature cord circuit, glutamatergic transmission is not needed for spontaneous episodes of activity at E12.

Cholinergic transmission plays a major role in the episodic activity in the maturing chick spinal motor circuit (Milner and Landmesser, 1999), and ACh could be released either from interneurons or from motoneuron axon collaterals. It is generally accepted that motoneurons release $\mathrm{ACh}$ and that at later developmental stages, the rat cervical and lumbar cord contains cholinergic interneurons (Phelps et al., 1990). Endogenously released ACh from either source could be acting via muscarinic receptors, a variety of nicotinic receptors, or both. The latter, in which pharmacological and channel properties are determined by their subunit composition, are widely expressed in the nervous system (Dwoskin and Crooks, 2001). However, a detailed characterization of the spatial expression patterns of the different receptor subtypes has not been performed during early mouse cord development. Therefore, we tested a variety of cholinergic 
antagonists to see whether they affected rhythmic spontaneous activity.

Most general as well as more specific (i.e., affecting specific subunit combinations) nicotinic ACh receptor (nAChR) antagonists slowed the frequency of bursting activity, so that the interepisode interval (Fig. 2B) was significantly increased. The application of both low and high doses of general nAChR antagonists, such as mecamylamine ( 1 and $20 \mu \mathrm{M}$ ) and dTC (5 and $10 \mu \mathrm{M}$ ), increased the time between episodes by approximately fourfold (Fig. $2 B ; p<0.05)$. Similar effects were also seen with the addition of the neuromuscular nAChR antagonist decamethonium bromide, suggesting the presence of $\alpha 1$ receptors $(p<0.05)$. However, the specific $\alpha 7 \mathrm{nAChR}$ antagonist MLA ( $1 \mu \mathrm{M})$ had no affect on spontaneous episodes of activity $(p>0.05)$. Interestingly, $\mathrm{DH} \beta \mathrm{E}$ $(5 \mu \mathrm{M})$ rapidly and completely abolished the rhythmic episodes of activity (Fig. $2 C)$. When propagating episodes were blocked with $\mathrm{DH} \beta \mathrm{E}$, local episodes (Fig. $1 D$ ) began to occur, although their amplitude and duration were smaller, and they were less frequent compared with the control episodes (data not shown). These local episodes from sciatic and crural nerves occurred randomly, were not synchronized throughout the cord (data not shown), and appear to represent the activation of local circuits. They will be discussed in more detail later. $\mathrm{DH} \beta \mathrm{E}$ is a competitive antagonist of $\beta 2$ subunits in combination with $\alpha 3$ and $\alpha 4$ subunits. $\mathrm{DH} \beta \mathrm{E}$ also has high affinity for $\alpha 4 \beta 4$ nicotinic receptors (Dwoskin and Crooks, 2001). Muscarinic ACh receptors could also be playing a role in rhythmic spontaneous activity. However, the muscarinic ACh receptor antagonist atropine $(10 \mu \mathrm{M})$ had no affect on rhythmic spontaneous activity $(p>0.05)$. These data indicate that endogenously released $\mathrm{ACh}$ acting through $\mathrm{DH} \beta \mathrm{E}$-sensitive nicotinic receptors plays a critical role in the generation of spontaneous bursting episodes in the early mouse spinal motor circuit.

As demonstrated above, cholinergic transmission was required for rhythmic spontaneous activity; however, the classically inhibitory transmitters GABA and Gly have been shown to modulate transmission in the maturing embryonic spinal cord (Sernagor et al., 1995; Nishimaru et al., 1996, Branchereau et al., 2002). Furthermore, it is known that both GABA and Gly can be excitatory at early developmental stages in various regions of the nervous system (Wu et al., 1992; Reichling et al., 1994; Chen et al., 1996; Owens et al., 1996). When the $\mathrm{GABA}_{\mathrm{A}}$ receptor antagonists bicuculline $(50 \mu \mathrm{M})$ (Fig. $2 D)$ and picrotoxin $(5 \mu \mathrm{M})$ were applied to E12 mouse spinal cords, both increased interepisode intervals (2.8-fold increase compared with control; $p<0.05$ ) (Fig. $2 D)$. However, phaclofen and hydrosaclofen, $\mathrm{GABA}_{\mathrm{B}}$ receptor antagonists (Fig. 2D), and 1,2,5,6-tetrahydropyridin-4-yl)methyl phosphinic acid (TPMPA) (Fig. $2 D)$, a GABA $_{\mathrm{C}}$ receptor antago-

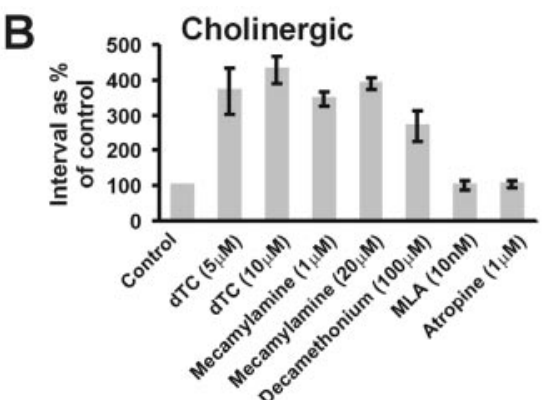

D
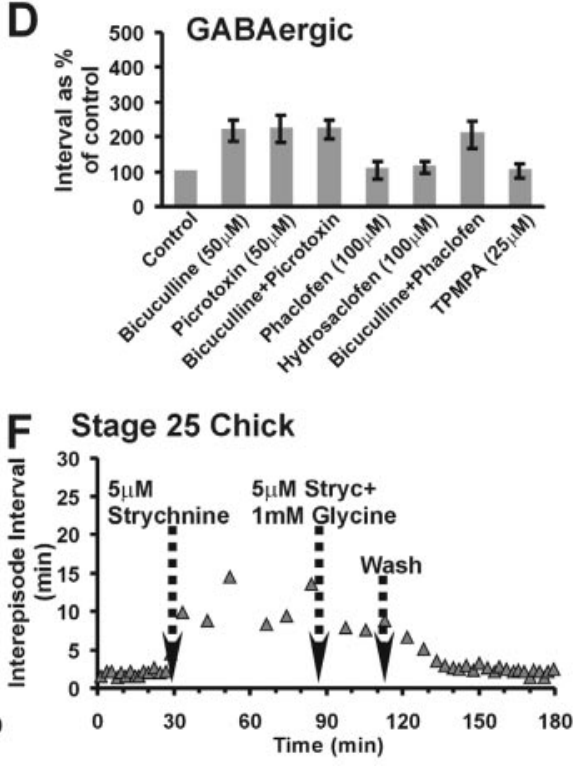

Figure 2. Early embryonic spontaneous episodes of activity require glycinergic and cholinergic but not glutamatergic transmission. $A$, In the $\mathrm{E} 12$ spinal cord, glutamate receptor agonists and antagonists did not affect spontaneous activity. $B$, In contrast, many antagonists (some considered general blockers and others directed against specific nicotinic subunit compositions; see antagonist with high sensitivity toward $\alpha 3 \beta 2$ and $\alpha 4 \beta 4$ receptors) abolished spontaneous episodes of activity (O. D, In the lofen, $100 \mu \mathrm{m}$; Hydrosaclofen, $50 \mu \mathrm{M}$ ) and $\mathrm{GABA}_{\mathrm{C}}$ receptor antagonist (TPMPA, $100 \mu \mathrm{m}$ ) were without effect. The Gly receptor antagonist strychnine (Stryc, $5 \mu \mathrm{m}$ ) completely suppressed rhythmic episodes in the E12 mouse spinal cord $(E)$ and greatly slowed the frequency of episodes in the stage 25 chicken spinal cord $(F)$.

nist, had no effect on the rhythmic spontaneous activity $(p>$ $0.05)$. These data indicate that endogenously released GABA acting via $G_{A B A}$ receptors contributes to the excitatory drive in the early circuit, but that it is not required for the generation of spontaneous episodes of activity. Similar affects of GABA were also found in the early chick spinal motor circuit (E5; Milner and Landmesser, 1999).

To assess the effect of Gly, which is inhibitory in more mature cord circuits, we bath applied the Gly receptor antagonist strychnine $(1-5 \mu \mathrm{M})$. This dramatically increased the interepisode intervals and completely abolished spontaneous bursting activity within $60 \mathrm{~min}$ (Fig. $2 E ; n=5$ ), indicating that at this developmental stage, Gly is excitatory. Interestingly, during bath application of strychnine, multiple local episodes of smaller amplitude and duration occurred between episodes. Although propagating episodes within the left crural nerve and left sciatic nerve were found to be in-phase with each other, local episodes were not in-phase with each other (data not shown). However, they persisted after propagating episodes of activity were abolished. The effect of inhibiting glycinergic transmission with strychnine was 
also tested in the E5 chick spinal cord. Although the intervals between episodes increased considerably, they were never completely abolished (Fig. 2 F). Strychnine has also been shown to block nicotinic $\alpha 7$ receptors (Matsubayashi et al., 1998). However, because the $\alpha 7$ receptor antagonist MLA had no effect on spontaneous episodic activity in either the E5 chicken (Milner and Landmesser, 1999) or the E12 mouse (this study) (Fig. 2 B), it is unlikely that the actions of strychnine are via nicotinic $\alpha 7$ receptors.

In summary, ACh and Gly were the two transmitter systems required for the generation of spontaneous propagating activity in E12 mouse cord. Furthermore, the fact that $\mathrm{DH} \beta \mathrm{E}$ was able to rapidly block spontaneous bursting, whereas spontaneous episodes could persist for up to $1 \mathrm{hr}$ in the presence of the glycinergic antagonist strychnine, points to a central role of cholinergic transmission in this system. It is presently unclear why strychnine took so long to block spontaneous bursting. Although strychnine may behave as a slow-acting alkaloid in several systems in culture (Boehm et al., 1997; Levi et al., 1999), in E15.5 rat spinal cord slices (Kulik et al., 2000), the antagonistic affects of strychnine on Gly receptor activation were immediate. Consistent with this observation, we found that Gly, when applied alone, elicited a series of bursts, and these could be blocked by strychnine as early as 15 min. This suggests that strychnine is blocking glycinergic receptors. However at this time point, spontaneous propagating episodes were still occurring. One explanation for why strychnine took so long to block the propagating episodes could be that in the absence of glycinergic transmission, other inputs such as cholinergic are able to sustain bursting for some length of time. However, little is known about glycinergic circuitry in the spinal cord at this stage in development of either the mouse or the chicken.

\section{Antidromic activation of motoneurons can elicit an episode that propagates throughout the lumbar cord}

The ACh that was shown to play a critical role in generating spontaneous propagating episodes may arise from motoneurons or from interneurons. Because cholinergic interneurons have not been observed in the E12 mouse spinal cord, we tested the possible role of motoneurons in generating propagating activity. Characterization of the E9-E12 chick spinal cord circuit (Chub and O'Donovan, 1998; O'Donovan et al., 1998; Fedirchuk et al., 1999) has shown that spontaneous episodes result when recurrent excitatory connections between motoneurons and interneurons reach a threshold that elicits an episode that propagates throughout the cord. This then results in a network depression so that episodes cannot be elicited for a period after a spontaneous episode. However, stimulation of descending input (stimulation of the cervical or thoracic region of the cord) after this period will elicit an episode of the same amplitude and duration as spontaneous propagating episodes. Similarly, in E12 mouse cord, after sufficient recovery from network depression, we found that activation of descending inputs, either at thoracic (Fig. $3 B, 1$ ) or more rostral lumbar (Fig. 3B, 2) levels, elicited a burst of activity that propagated throughout the circuit and that could be recorded with a delay from the right sciatic nerve. Such circuit activation could also be elicited by direct activation of motoneurons by stimulation of the segments containing the recorded motoneurons and interneurons (Fig. 3B, 3). As expected, such direct activation of the motoneurons elicited a compound action potential in the sciatic nerve (Fig. 3C, 3). Note that the latency of this mode of activation was considerably decreased compared with more rostral stimuli.

To determine whether activation of motoneurons alone was
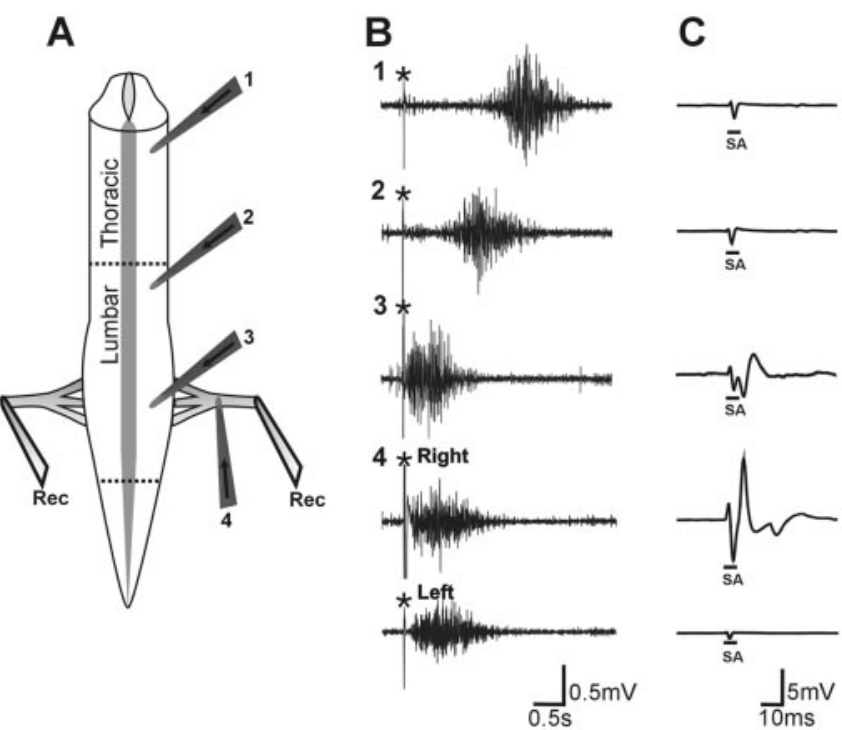

Figure 3. Triggering of episodes by different sources of stimulation. A, Diagram of lumbar and thoracic regions of spinal cord. Stimulation electrodes (black) were placed at low thoracic (1), at lumbar segment 2 (2), directly over the recorded motoneurons (3), or directly onto the nerve from which the recording was made (4). $B$, The responses to each of these modes of stimulation are shown as bursts on a slow time base. $C$, The faster time base shows that only direct activation of large numbers of motoneurons by stimulating them directly in the cord or in the nerve proximal to the recording electrode resulted in a compound action potential. The stimulus artifact is noted by asterisks in the slow time base traces (left) and by SA in the faster time base traces (right). Antidromic activation of the motoneurons in the right sciatic nerve ( $B$, 4 ) elicited a bursting episode that propagated throughout the cord, including left sciatic motoneurons.

capable of eliciting a burst that propagated throughout the circuit, the right sciatic nerve was stimulated proximal to the recording site (Fig. 3B, 4, top trace). This stimulation also produced a burst of similar amplitude and duration as those elicited by descending input, presumably via retrograde activation of the circuit via motoneuron axon collaterals. Such antidromic activation of the right sciatic motoneurons was capable of activating the entire lumbar circuit, including the left sciatic motoneurons (Fig. $3 B, 4$, bottom trace). Motor nerve stimulation also produced a compound action potential distally, because of the synchronous activation of many motoneurons, as seen in the expanded time base recording (Fig. 3C, 4, top trace). No compound action potential accompanied the burst in the left sciatic motoneurons, because these neurons were not directly activated (Fig. 3C, 4, bottom trace). In addition, the burst recorded from this nerve occurred with some delay, as might be expected if activation were occurring via propagation of activity through the circuit.

Within the spinal motor circuit, motoneuron activation might simply reflect the output imposed by networks of interneurons. Alternatively, motoneurons might also play an active role in generating or contributing to the activation of the cord circuit via cholinergic transmission from axon collaterals. The data presented above indicate that motoneuron activation alone can elicit an episode of activity that propagates throughout the cord. Furthermore, this mode of circuit activation occurred even when the dorsal roots were cut to prevent activation via sensory input (data not shown). In fact, at E12, dorsal root ganglion neurons are just beginning to project axons centrally (Ozaki and Snider, 1997). Afferents that project out ventral roots have been described in postnatal animals, and ventral root stimulation in P12-P20 rats (Jiang et al., 1991) produced glutamatergic EPSPs onto motoneu- 
rons. However, we have not seen any anatomical evidence for such afferents in the E12 mouse cord. Furthermore, the bursts that were elicited by stimulation of peripheral nerves were not blocked by glutamatergic antagonists. Taken together, our data indicate that the pattern of motoneuron activation during spontaneous episodes may not simply reflect the output of a circuit comprising interneurons, but also that motoneurons may activate the circuit presumably through axon collaterals (Cullheim et al., 1977; Lagerbäck et al., 1981).

We confirmed, by retrograde HRP labeling after direct injection of HRP into spinal nerves, that E12.5 mouse motoneurons had numerous axon collaterals that branched extensively (Fig. 4A,B). These axon collaterals appeared to terminate both within the motor columns and nearby regions of the cord as well as in the lateral and ventral white matter tracts (Fig. 4A; data not shown) (for embryonic cat and chick, see Ramon y Cajal, 1952a,b). To label all of the cholinergic processes including axon collaterals, the sections were labeled with antibodies directed against the VCAT. At E12, this labeled the motoneuron somas in the lateral motor column as well as their neurites (Fig. 4C). Similar to the HRP labeling, large numbers of VCAT-positive neurites were found in the lateral and ventral white matter tracts (Fig. 4C-E, LF, VF). VCATpositive neurites also emerged from the lateral motor column to terminate in the ventral spinal cord dorsal and medial to the motoneuron containing lateral motor column (Fig. 4C, asterisks). These data suggest that by E12.5, motoneurons have axon collaterals that not only project locally but also project rostrally or caudally within the ventral and lateral funiculi. Although we cannot exclude the possibility that some of these VCAT-stained processes are dendrites, their overall distribution and morphology differed markedly from those of the dendritic processes of motoneurons that we observed with HRP back-labeling. Thus, we believe that most VCAT-positive neurites are axon collaterals of motoneurons. By using a combination of ChAT and VCAT labeling, we observed that most cholinergic neurons at E12.5 reside within the lateral motor column and are thus likely motoneurons (data not shown). However, by E15 in the rat, a cholinergic population of interneurons that resides medial to the motoneurons has been observed (Phelps et al., 1990; Barber et al., 1991). Although we occasionally observed ChAT-positive
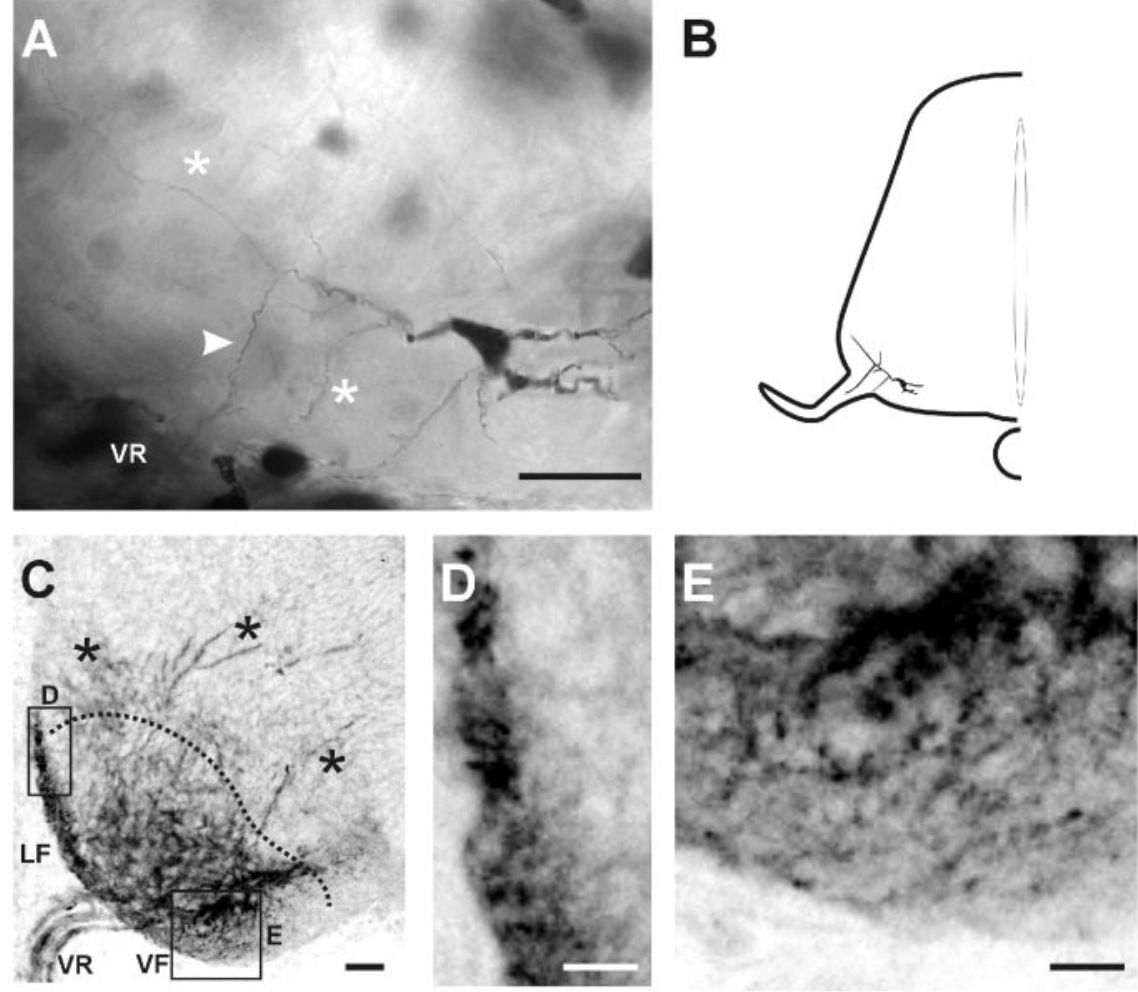

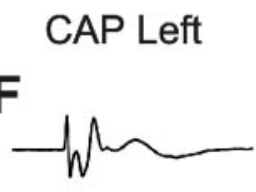

$\overline{S A}$
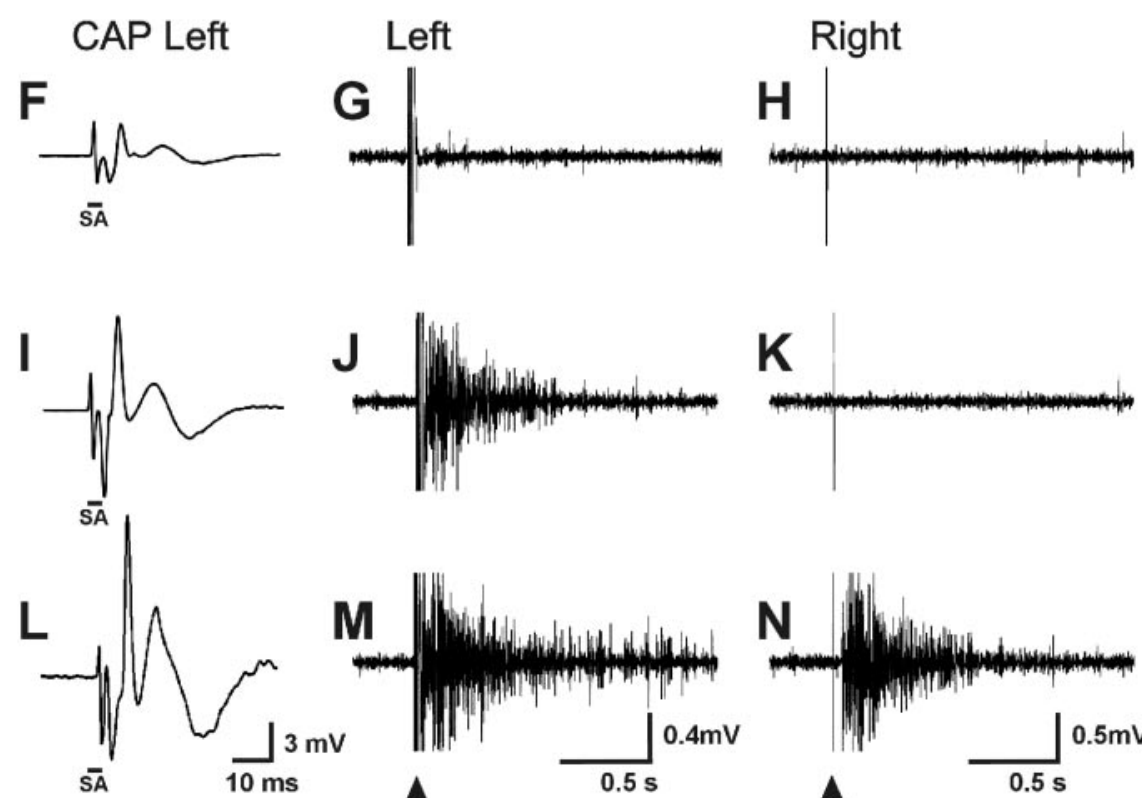

SA

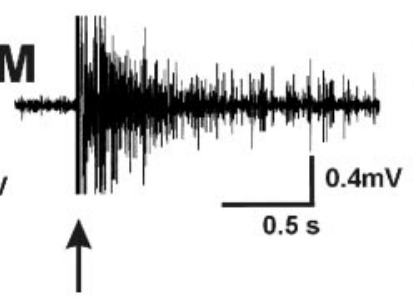

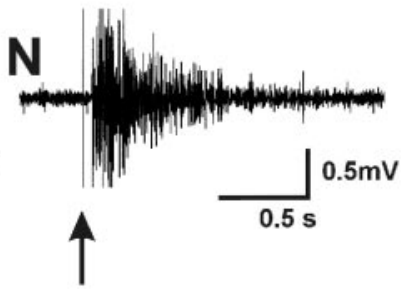

Figure 4. Activation of a minimal number of motoneurons is required to elicit an episode that propagates throughout the cord. $A$, An E12.5 motoneuron retrogradely labeled with injection of HRP into spinal nerve reveals the cell soma, its axon projecting out the ventral root (VR, arrowhead) and axon collaterals (some denoted by asterisks) within the ventral horn. $B$, Inset showing location of labeled motoneuron in A. C, Immunohistochemistry of VCAT labeling also at E12.5 displays VCAT-positive neurites projecting from the lateral motor column into the ventral funiculus $(V F)$, lateral funiculus $(L F)$, and interneuron-containing regions dorsal and medial to the lateral motor column (asterisks). Scale bars, $25 \mu \mathrm{m}$. D, E, Inset from $C$ of lateral and ventral funiculi, respectively, displaying VCAT-positive neurites. $F-N$, The left sciatic nerve trunk was stimulated with increasing intensity while recording from both left $(G, J, M)$ and right $(H, K, N)$ sciatic nerves. $F$, At low currents, some motoneurons were activated, resulting in a small compound action potential $(C A P)$ in the sciatic nerve. However, this did not elicit a burst within the spinal motor circuit $(G, H)$. I, At a higher current and with a larger number of motoneurons activated, as assessed from the CAP, a burst was elicited within the local circuit on the left $(J)$ but did not activate an episode throughout the spinal cord $(K)$. At maximal stimulus for motoneuron activation $(L)$, an episode was elicited that propagated throughout the spinal cord $(M, N)$. 


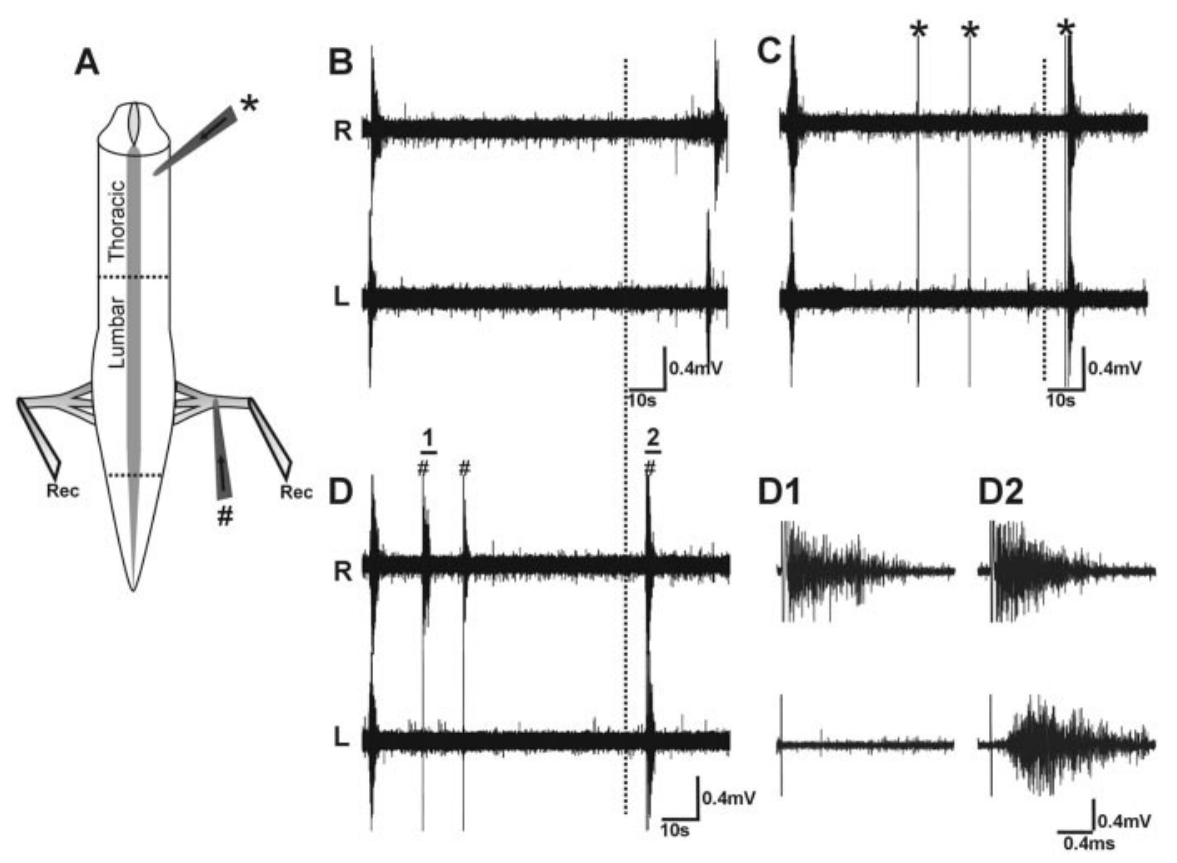

Figure 5. A local circuit can be activated during the period of spinal motor circuit depression. $A, B$, Spontaneous episodes of activity were recorded in the left and right sciatic nerves with an interepisode interval of $96.4 \pm 5.32 \mathrm{sec}$ (mean $\pm \mathrm{SE}$ ). The dotted line indicates the earliest time that a stimulus could evoke an episode of activity that propagated throughout the cord. C, Stimulation of descending input (asterisks) could not elicit a burst in the left or right sciatic nerve until the period after the dotted line. D, Maximal antidromic activation ( pound sign) of the motoneurons by stimulating the left sciatic nerve shortly after a spontaneous episode elicited bursts of activity in the stimulated sciatic nerve (top trace) but not in the contralateral nerve (bottom trace). D1, D2, Expanded time base of portions of the record. Retrogradely stimulating the left sciatic (D1), even at early times after a spontaneous episode, was capable of eliciting a burst in those motoneurons (top trace). However, such a burst did not spread throughout the lumbar cord, as indicated by the absence of a burst in the right sciatic nerve (bottom trace). Stimulation later in the interepisode interval (D2), however, when the entire lumbar circuit had recovered from depression, elicited a burst in the stimulated motoneurons (top trace), which subsequently elicited a burst with greater latency in the contralateral sciatic nerve (bottom trace).

neurons in this region in E12.5 mouse cord, retrograde HRP labeling showed that at this time, some motoneuron somas had not yet migrated into the lateral motor column and might account for these cholinergic neurons. Unambiguous identification of this population as interneurons as opposed to migrating motoneurons will require assessing their expression of transcription factors (Saueressig et al., 1999; Pieriani et al., 2001). In summary, although we cannot exclude the presence of a small number of cholinergic interneurons in the E12-E12.5 mouse cord, most cholinergic axons appear to arise from motoneurons.

\section{Antidromic activation of motoneurons can elicit either local or propagating episodes}

When a burst is activated by stimulating a motor nerve, only motoneurons, which have axons in that nerve, can initiate the burst. In all previous experiments, we used a stimulus that elicited a maximal compound action potential and were presumably activating all of the motoneurons within that nerve trunk. To determine whether the generation of a burst within those motoneurons and the subsequent propagation of an episode of activity throughout the cord required activation of a given proportion of motoneurons, stimulation of the motor nerve was performed at increasing stimulus intensities. To avoid circuit depression, compound action potentials and bursts were elicited only during the period when stimuli were capable of activating the entire circuit.

At low current levels, single stimuli evoked small-amplitude compound action potentials (Fig. $4 F$, left) that did not activate a burst within the circuit of stimulated motoneurons (Fig. 4G,H).
As the stimulus intensity was increased, activating a larger proportion of the motoneurons, as evidenced by the compound action potential (Fig. 4I), a burst could be elicited locally within the stimulated motoneurons (Fig. $4 \mathrm{~J}$ ). However, it did not propagate throughout the cord, as seen by the absence of a burst on the contralateral side (Fig. $4 K$ ). However, if the stimulus was further increased (Fig. 4L) to activate a larger proportion of motoneurons, the localized burst propagated throughout the cord, activating the contralateral sciatic motoneurons (Fig. $4 M, N)$. Because the amplitude of the bursts, once triggered, did not increase with increasing stimulus intensity, our data suggest a triggered all-or-none response with a threshold for initiation (Ritter et al., 1999). These data suggest that for the generation of a local burst, a sufficient number of motoneurons within a population must be activated. Furthermore, an even larger number of motoneurons within that population must be activated for that local burst to generate an episode that propagates throughout the cord.

\section{Local and propagating episodes differ in their sensitivity to circuit depression} The experiments described above revealed the existence of a local circuit that could be activated by antidromic activation of the motoneurons. Furthermore, by applying superthreshold stimuli, we observed that this local circuit could be activated during the period of overall circuit depression, but that such local episodes did not propagate throughout the cord. In the E9-E11 chick cord, an episode of spontaneous activity elicits depression of the circuit so that a second stimulated episode cannot be elicited for a significant portion of the interepisode interval (Chub and O'Donovan, 1998, 2001; Fedirchuk et al., 1999). Similar results were observed in the E12.5 circuit. Two spontaneous episodes of activity in the right (top) and left (bottom) sciatic nerves are shown in Figure $5 B$. Attempts to activate the circuit via descending inputs were not successful if stimuli were applied at any point left of the dotted line. In the example shown in Figure $5 C$, the first two stimuli (asterisks) did not elicit a burst, whereas that delivered after the period of circuit depression did (Fig. 5B).

In contrast, it was possible to elicit a local burst via antidromic activation of the right sciatic nerve, even after short intervals following a spontaneous episode (Fig. 5D, 1, pound sign). However, such episodes did not propagate throughout the cord, as shown by the lack of a burst in the left sciatic nerve. After recovery from circuit depression (Fig. 5D, 2, pound sign), activation of an episode from the right sciatic nerve propagated throughout the cord, resulting in a burst in the left sciatic nerve. The expanded time base records at right show that local bursts elicited during circuit depression, although slightly smaller (Fig. 5D, 1), were quite similar to bursts (Fig. $5 D, 2$ ) that propagated throughout the cord. In summary, the data indicate the existence of a local circuit that can be activated within the larger spinal motor circuit. Furthermore, these results also show that this early (E12) mouse 


\section{A Control}

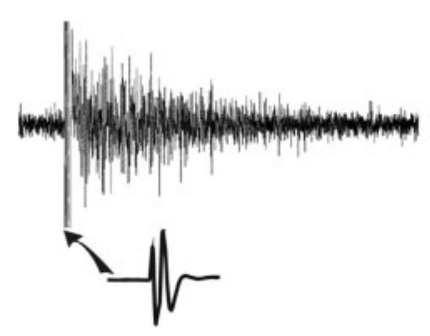

$100 \mu \mathrm{M}$ Carbenoxolone (Gap Junction Blocker)

B Control

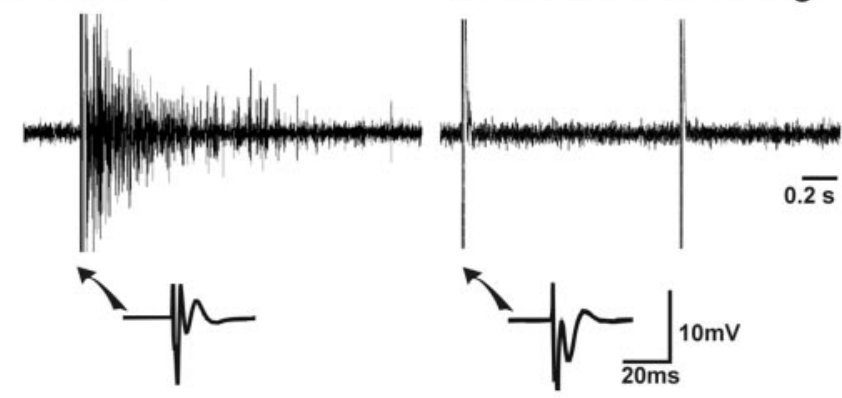

Figure 6. Antidromic stimulation activates the local circuit through chemical transmission. $A$, Antidromic activation of the local circuit was not affected by application of the gap junction blocker carbenoxolone (100 $\mu \mathrm{m})$. B, Local circuit activation was abolished in a solution of high $\mathrm{Mg}^{2+}$ and low $\mathrm{Ca}^{2+}$. Insets on a faster time base below the traces show the compound action potential produced by stimulation of the motor nerve trunk $(A, B)$.

spinal motor circuit undergoes circuit depression, similar to that found in the more developed chick spinal motor circuit (E9-E11; Chub and O'Donovan, 1998, 2001; Fedirchuk et al., 1999). Together, these data suggest that multiple local circuits might together constitute the overall motor circuit, and that their synchronous activation produces the rhythmic spontaneous activity observed in the E12 mouse spinal cord.

\section{Local and propagating episodes differ in their requirement} for electrical transmission

Previously we demonstrated that rhythmic spontaneous activity required both electrical and chemical transmission. In addition, we have described a localized circuit in the E12 mouse spinal cord that can be activated by the activation of motoneurons. This circuit is capable of eliciting propagating episodes and is able to be activated during times when the overall circuit remains depressed. We next wished to address whether electrical or chemical transmission or both contribute to the activation of the local circuits. To block electrical transmission, carbenoxolone, a gap junction inhibitor, was added, and this abolished spontaneous propagating episodes (Fig. $1 F$ ). Subsequent antidromic activation of the motoneurons was still able to elicit a local burst of activity, similar in amplitude and duration to the control local burst (Fig. 6A). Thus, motoneurons do not require gap junction coupling to elicit a burst within the local circuit.

The importance of chemical transmission was investigated by perfusing the spinal cord with low $\mathrm{Ca}^{2+}(0.2 \mathrm{~mm})$ and high $\mathrm{Mg}^{2+}$ (7.0 mM) to block transmitter release. This completely abolished spontaneous propagating episodes as well as the ability of antidromic activation of the motoneurons (Fig. $6 \mathrm{~B}$, inset) to elicit a local episode. Thus, activation of the local circuit is brought about by chemical transmission.
Neither GABAergic nor glycinergic transmission is necessary for activation of the local circuit by antidromic motoneuron stimulation

The motoneuron axon collaterals could be making synaptic contacts with either interneurons or motoneurons. We demonstrated that both GABA and Gly transmission influenced spontaneous activity in an excitatory manner. Glutamic acid decarboxylase 65 (GAD65), a marker for GABAergic neurons, has been detected as early as E13 in the rat in ventrally located neurons that not only project to the ventral commissure but also have projections into the region of the ventral horn and surrounding funiculi (Phelps et al., 1990). GAD65 staining of the E12.5 mouse spinal cord produced similar results (data not shown). Therefore, we examined whether GABAergic or glycinergic transmission was required to elicit a burst within the local circuit by antidromic motoneuron activation. When glycinergic transmission was blocked by strychnine $(5 \mu \mathrm{M})$, stimulation of descending inputs no longer elicited an episode of activity, and this occurred within $15 \mathrm{~min}$ of drug application (Fig. $7 \mathrm{~A}$, top trace). However, direct activation of the motoneurons in the lumbar cord still elicited an episode (middle trace). Furthermore, retrograde activation of the circuit via stimulation of the motoneurons was not affected by strychnine throughout the time course of drug application (bottom trace). These data combined with our previous observations indicate that although glycinergic transmission is required for the propagation of spontaneous episodes throughout the cord, it is not required for the activation of the local circuit.

To assess the role of GABAergic transmission in the antidromic activation of the local circuit, picrotoxin $(50 \mu \mathrm{M})$ was applied (Fig. $7 B$ ). As shown previously, blocking $\mathrm{GABA}_{\mathrm{A}}$ receptors slightly slowed the frequency of spontaneous episodes but had no affect on the ability of descending input to elicit a burst (Fig. 7B, top trace) or through direct cord activation of the motoneurons (middle trace). The activation of the local circuit via antidromic stimulation of the motoneurons was also unaffected by picrotoxin (bottom trace). To remove both glycinergic and GABAergic transmission from interneurons, both picrotoxin and strychnine were applied together (Fig. 7C), slightly decreasing the amplitude of the burst generated by directly activating the motoneurons at the lumbar level of the spinal cord (top trace). However, activation of local episodes via antidromic activation of the motoneurons was unaffected (bottom trace). Glutamate antagonists APV and CNQX also had no effect on the activation of local episodes by antidromic motoneuron activation (data not shown). We sometimes observed slight changes in burst duration and amplitude with drug treatments, perhaps because of less synchronous activation of the circuit (Fig. $7 B, C$ ), but these were not quantified.

\section{Motoneuron activation elicits local episodes via nicotinic receptors that differ from those required for spontaneous propagating episodes}

We have demonstrated that cholinergic transmission is required for spontaneous propagating episodes in the E12 mouse spinal cord. However, many of the general nicotinic ACh receptor antagonists, such as dTC and mecamylamine, did not completely abolish spontaneous activity (Fig. $2 \mathrm{~B}$ ). Within the ventral horn at later stages of development, cholinergic synapses have been shown to originate both from collaterals of neighboring motoneurons and from nearby interneuron populations (Cullheim et al., 1977; Lagerbäck et al., 1981; Wetts and Vaughn, 2001). It was therefore important to determine the extent to which cholin- 

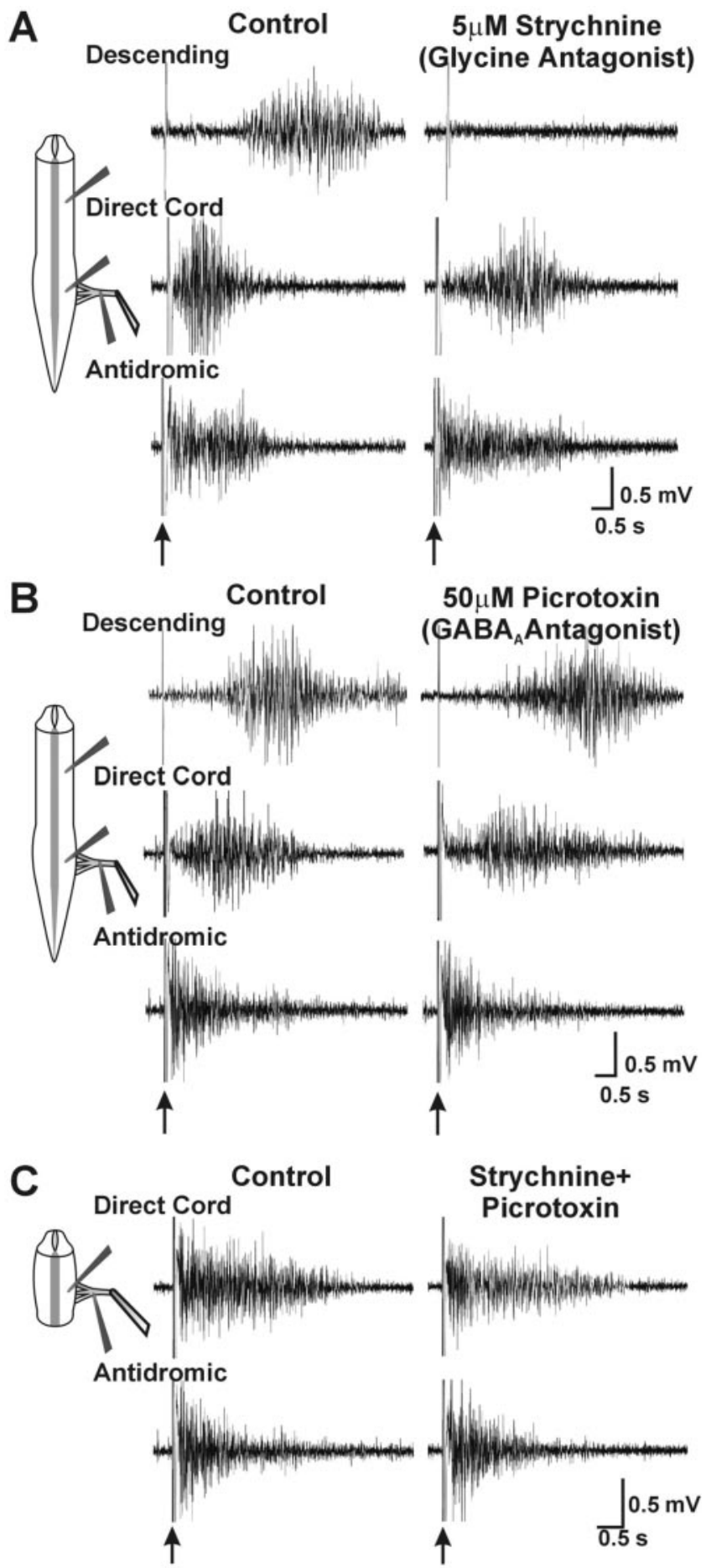

Figure 7. Activation of the local circuit by antidromic stimulation of motoneurons is independent of GABAergic and glycinergictransmission. A, Although strychnine $(5 \mu \mathrm{M})$ did block the ability of a descending input to elicit an episode, bursts elicited by direct or antidromic activation of the motoneurons were only slightly affected. $B$, In addition, picrotoxin $(50 \mu \mathrm{m})$ had no effect on activation via the descending input and little effect on direct or antidromic activation of the motoneurons. C, The combination of both drugs slightly decreased the response elicited by direct activation of the cord segments containing the motoneurons (top trace) but had no effect on the burst elicited by antidromic activation of the motoneurons (bottom trace).

ergic transmission between motoneurons, versus that between interneurons and motoneurons, contributed to the activation of bursting episodes. Although a variety of cholinergic antagonists are available that are thought to be specific for various nicotinic subunit combinations (Dwoskin and Crooks, 2001), these specificities have not been demonstrated for developing nicotinic receptors. Therefore, dTC, which is considered a nonspecific $\mathrm{nAChR}$ antagonist in more mature systems, may only block a subset of nAChR in the early spinal motor circuit. Thus, to completely abolish cholinergic transmission, we chose to prevent the uptake of ACh into synaptic vesicles with vesamicol (100 $\mu \mathrm{M}$; Marshall and Buccafusco, 1987; Prior et al., 1992). This abolished rhythmic spontaneous activity ( $\sim 30 \mathrm{~min}$; data not shown), antidromic activation of the local circuit (Fig. $8 A$ ), as well as activity elicited by direct stimulation of the local circuit (Fig. $8 A$ ).

Given that blockade of cholinergic transmission prevented local circuit activation, we examined several nAChR antagonists to characterize the relevant receptors. After application of $\mathrm{DH} \beta \mathrm{E}$ $(5 \mu \mathrm{M})$, which blocked spontaneous propagating episodes, stimulation of descending inputs no longer elicited an episode (Fig. $8 B$, top traces). In contrast, $\mathrm{DH} \beta \mathrm{E}$ had no effect on local bursts of activity, activated by either direct stimulation of the lumbar cord containing the recorded motoneurons (middle traces) or by antidromic activation of motoneurons (bottom traces). However, these bursts were confined locally and did not propagate throughout the cord, as they would have in the absence of $\mathrm{DH} \beta \mathrm{E}$. Thus, it appears that endogenously released ACh acting via $\mathrm{DH} \beta \mathrm{E}$-sensitive receptors is required for propagation of activity throughout the cord.

Endogenously released $\mathrm{ACh}$ was also required for effective activation of the local circuit but did so via different receptors. Although mecamylamine $(20 \mu \mathrm{M})$ or dTC $(10 \mu \mathrm{M})$ had no effect on the activation of the cord circuit via descending input (data not shown), each of these nicotinic antagonists reduced the amplitude of bursts elicited by antidromic activation of the motoneurons and when applied together almost completely suppressed such local bursts (Fig. 8C). These observations suggest that dTC and mecamylamine are mainly blocking cholinergic transmission in the local circuit, possibly between motoneurons.

Either cholinergic or GABAergic transmission can elicit a local burst in response to direct cord stimulation

Direct stimulation of the ventral spinal cord would be expected to activate both motoneurons and nearby interneurons. As discussed above, the combination of mecamylamine and dTC was able to essentially block the local burst elicited by antidromic motoneuron activation. In contrast, these two drugs together (Fig. 9B), or even with the addition of $\mathrm{DH} \beta \mathrm{E}$ (data not shown), only modestly reduced the amplitude of a local burst elicited by direct cord stimulation. However, when the $\mathrm{GABA}_{\mathrm{A}}$ antagonist picrotoxin $(50 \mu \mathrm{M})$ was also added, the burst was virtually abolished (Fig. 9C). As shown previously (Fig. 7A,B), picrotoxin or strychnine when applied alone had almost no effect on the burst elicited by direct cord stimulation. These data taken together suggest that the local circuit comprises a cholinergic pathway that presumably arises from motoneuron axon collaterals acting on other motoneurons and that does not require activation of GABAergic or glycinergic interneurons and a second pathway that activates GABAergic and glycinergic neurons and that does not require the cholinergic transmission from the motoneuron collaterals.

\section{Blockade of the local circuit abolishes rhythmic spontaneous activity}

As shown previously, mecamylamine, dTC, or picrotoxin alone did not block the spontaneous propagating episodes (Fig. 3). In addition, blocking either of the local pathways described above 
A

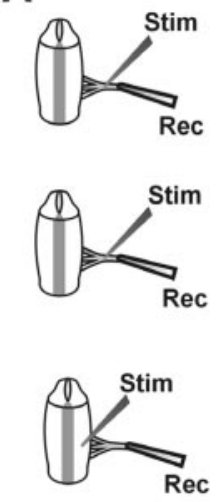

Antidromic Control

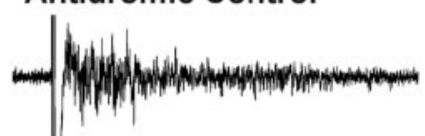

Antidromic $100 \mu \mathrm{M}$ Vesamicol

(Vesicular ACh Uptake Inhib.)

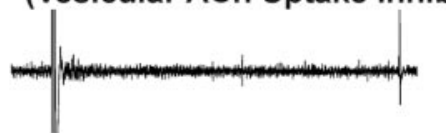

Direct Cord $100 \mu \mathrm{M}$ Vesamicol
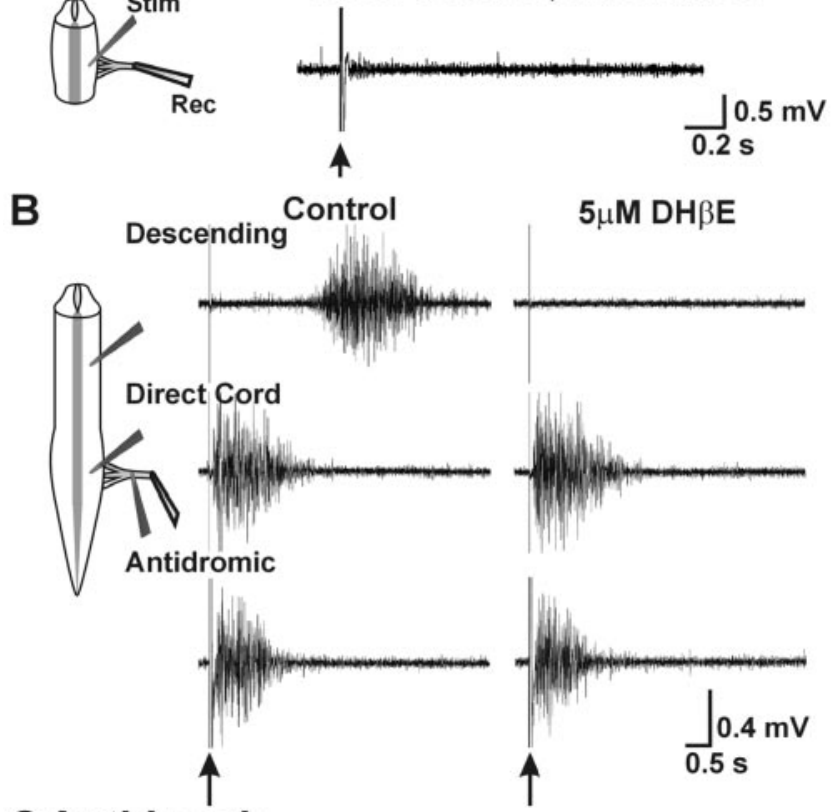

C Antidromic

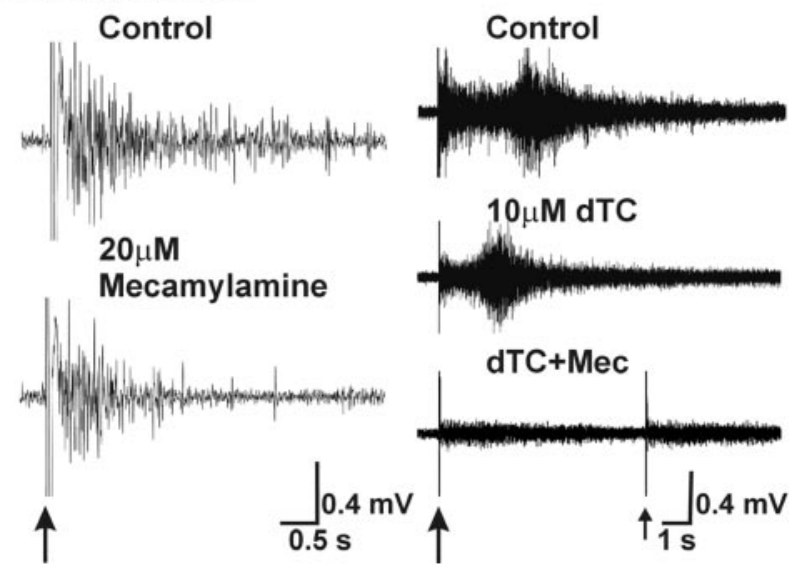

Figure 8. Cholinergic transmission is required to elicit episodes via both descending and antidromic stimulation of motoneurons, but the differing pharmacology suggests that different nicotinic subunits are used. $A$, Preventing cholinergic transmission with vesamicol, an inhibitor of ACh uptake into vesicles $(100 \mu \mathrm{M})$, prevented bursts elicited by both antidromic activation and direct activation of the cord segments containing the motoneurons. Stim, Stimulus; Rec, recording. B, Activation of the circuit via a descending input was blocked by $5 \mu \mathrm{m} \mathrm{DH} \beta \mathrm{E}$ (top trace), whereas direct activation of the circuit by stimulating the lumbar cord (middle trace) or antidromic activation via stimulation of motoneurons (bottom trace) was unaffected. C, The amplitude and duration of the burst elicited by antidromic activation of the motoneurons was reduced by either $20 \mu \mathrm{m}$ mecamylamine (Mec, left) or $10 \mu \mathrm{m}$ dTC (right middle trace). The combination of mecamylamine and dTC essentially blocked antidromic activation of the circuit via motoneuron stimulation (right bottom trace; arrows indicate time of stimulation).
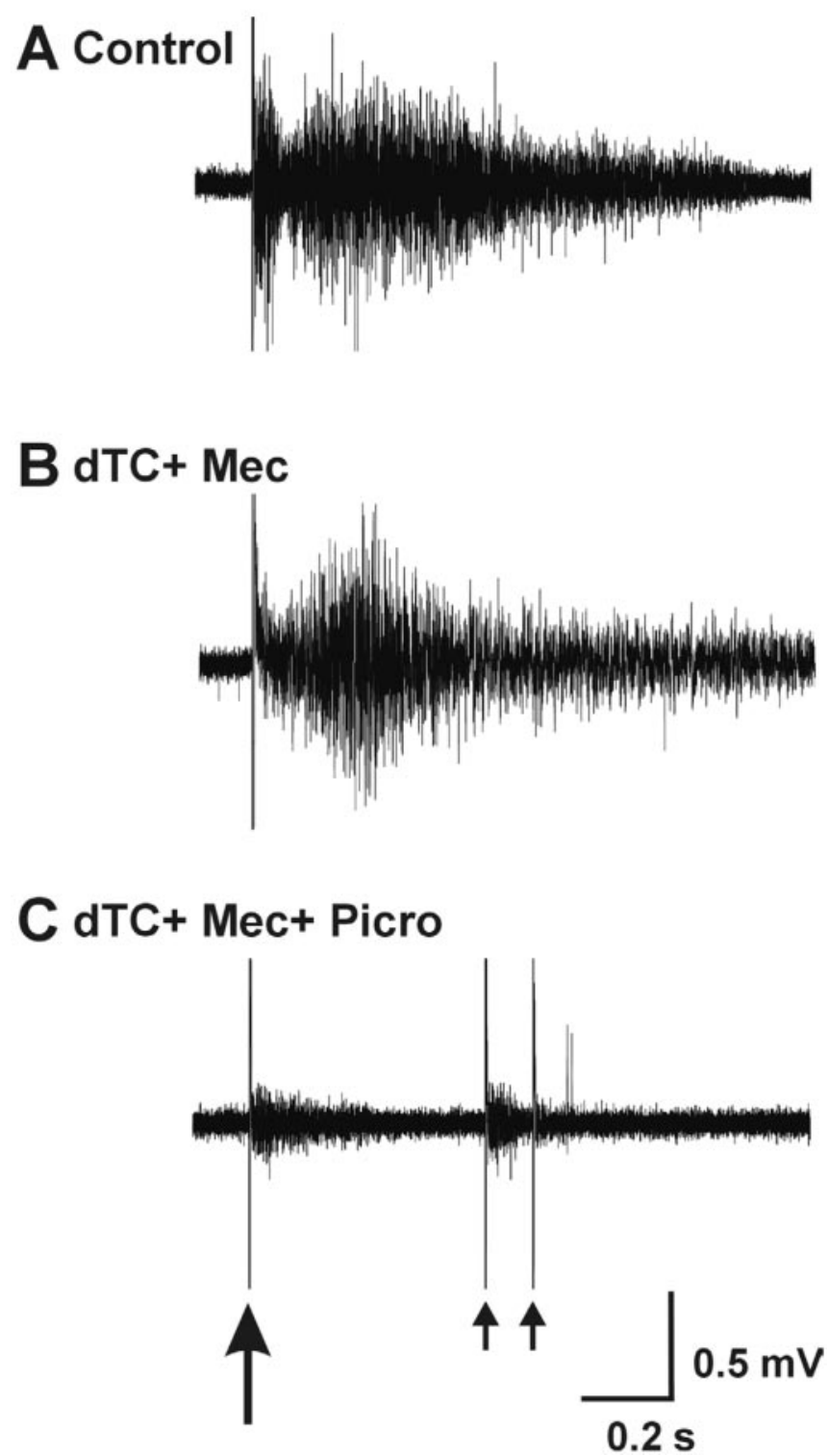

Figure 9. Direct activation of the local circuit can occur via either cholinergic or GABAergic transmission. $A, B$, The combination of $20 \mu \mathrm{m}$ mecamylamine (Mec) and $10 \mu \mathrm{m}$ dTC only slightly decreased the amplitude and duration of bursts elicited by stimulating the lumbar cord segments containing the motoneurons recorded from the sciatic nerve. C, Addition of $50 \mu \mathrm{m} \mathrm{pic-}$ rotoxin (Picro) to mecamylamine and dTC abolished most of response elicited by direct cord stimulation of the circuit (solid arrows indicate times of initial stimulation; small arrows indicate subsequent stimulations).

alone did not block spontaneous activity. However, blocking both the local cholinergic pathway via dTC and mecamylamine and the $\mathrm{GABA}_{\mathrm{A}}$ receptor pathway via picrotoxin blocked spontaneous activity (Fig. 10). These data appear to indicate that blocking transmission within the local circuit abolishes the generation of spontaneous episodes of activity. Therefore, both pathways for local circuit activation contribute to the propagation of spontaneous episodes of activity that propagate throughout the spinal cord.

\section{Discussion}

The nervous system is unique among developing systems in that electrical activity generated by emergent neural circuits can influence subsequent developmental processes (Katz and Shatz, 1996; Feller, 1999; O'Donovan, 1999; Ganguly et al., 2001). In this 


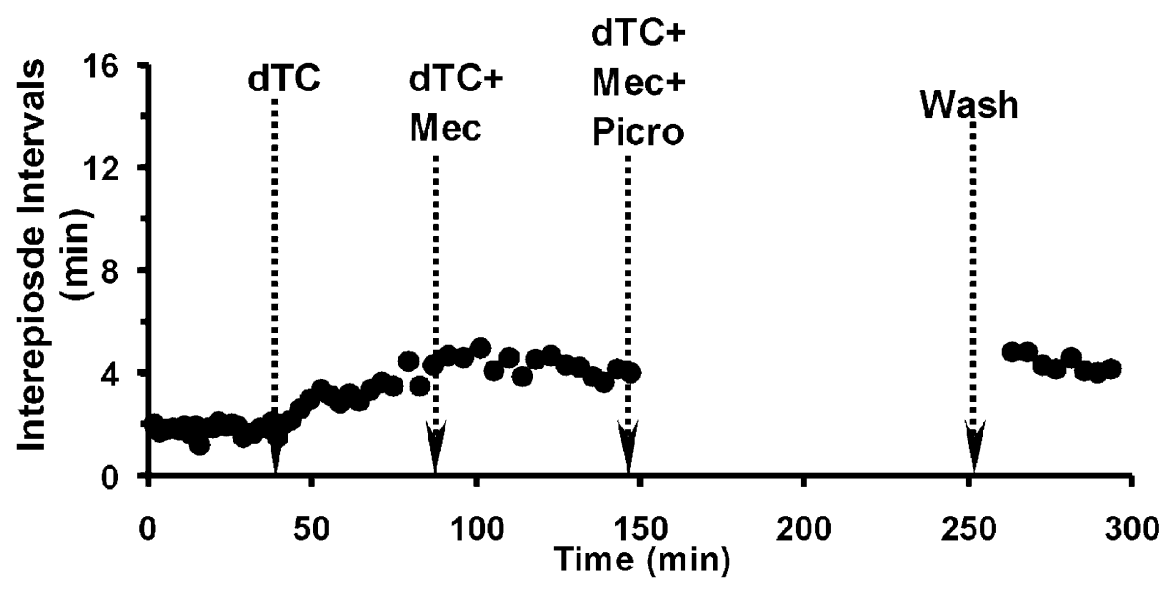

Figure 10. Blockade of the local circuit abolishes rhythmic spontaneous activity. The intervals between spontaneous episodes of activity were increased after application of $10 \mu \mathrm{m}$ dTC. The addition of $20 \mu \mathrm{m}$ mecamylamine (Mec) to dTC did not significantly increase interepisode intervals further. However, rhythmic spontaneous activity was abolished when $50 \mu \mathrm{m}$ picrotoxin (Picro) was added to the bath containing dTC and mecamylamine.

study, we have characterized the circuit that generates spontaneous rhythmic activity at the earliest times in mouse spinal motor circuit formation. Among our major findings are that both chemical and electrical transmission are required for such activity. Furthermore, we have shown that motoneurons themselves, acting via $\mathrm{DH} \beta \mathrm{E}$-insensitive nicotinic receptors, play an important role in generating this activity by participating in local circuits with GABAergic interneurons to provide the excitatory drive needed to elicit a local burst. However, for these bursts to propagate throughout the cord, cholinergic transmission via $\mathrm{DH} \beta \mathrm{E}$ sensitive receptors, glycinergic transmission, and electrical coupling via gap junctions is required. We will propose a model circuit that incorporates these findings, discuss this in relation to other developing motor circuits, and compare our results with rhythmic spontaneous activity elsewhere in the nervous system and its potential role in development.

\section{Spontaneous episodes of activity and the maturation of the} embryonic mouse spinal motor circuit

Our observations indicate that endogenously released ACh most likely from the motoneurons themselves and acting on nicotinic receptors is essential for the generation of spontaneous rhythmic activity in the E12-E12.5 mouse spinal cord, similar to results from the St25 (E4-E5) chick cord (Milner and Landmesser, 1999). In contrast to the more mature mouse, rat, and chick circuits, in which glutamate drives spontaneous activity (Nishimaru et al., 1996; Chub and O'Donovan, 1998; Branchereau et al., 2002), glutamate antagonists had no effect on spontaneous bursting activity in the E12 mouse cord, as was also observed for E14.5 rat cord (Nishimaru et al., 1996). A similar switch in excitatory drive from cholinergic to glutamatergic also occurs in spontaneous retinal waves during development (Feller et al., 1996; Catsicas et al., 1998; Wong et al., 1998; Zhou and Zhao, 2000).

In many developing systems, the classical inhibitory transmitters GABA and Gly have been shown to act in an excitatory manner ( $\mathrm{Wu}$ et al., 1992; Owens et al., 1996). Consistent with these observations, we found that their pharmacological blockade either slowed (for GABA) or blocked (for Gly) spontaneous episodes of activity. Blockade of glycinergic transmission has also been shown to block spontaneous episodes of activity in E15 rat cord (Nishimaru et al., 1996). With maturation, these excitatory responses to GABA and Gly become inhibitory (Wu et al., 1992) as the intracellular levels of chlo- ride are lowered, resulting in more negative equilibrium potentials for these transmitters. The intracellular chloride concentration is determined by the activity of a number of chloride transporters. In the mouse cord one of these, potassiumchloride cotransporter (KCC2), which extrudes chloride, thus reducing the intracellular chloride concentration (Payne, 1997), increases during development (Lu et al., 1999) and is in fact required for the switch of GABA transmission to inhibitory (Hubner et al., 2001). Intriguingly, in cultured hippocampal neurons, the expression of this transporter is itself controlled by GABA-mediated depolarization (Ganguly et al., 2001).

\section{Local circuits of motoneurons and} GABAergic interneurons underlie the central pattern generator for rhythmic spontaneous activity

Central pattern generators (CPGs) that produce rhythmic movements, such as respiration and locomotion, have been characterized in many systems. Most studies of the locomotor CPG in mouse or rat cord have focused on the neonatal period, when activity is usually evoked by the addition of neuromodulators such as serotonin (Cazalets et al., 1995; Kjaeruluff and Kiehn, 1996; Whelan et al., 2000). Clearly, early embryonic circuits in chick (Milner and Landmesser, 1999) and mouse differ from these more mature circuits in several important ways. Furthermore, this activity occurs spontaneously without the need for descending or afferent input. What drives this early bursting activity? Observations in the E10-E12 chick cord support a model in which recurrent excitatory connections between motoneurons and glutamatergic and possibly GABAergic interneurons result in a level of network excitation that reaches threshold for propagation throughout the cord (Ritter et al., 1999).

Our data on E12 mouse cord are consistent with such a model and provide strong support for motoneurons themselves playing a critical role in generating episodes of activity. We have shown that local circuits of motoneurons and GABAergic interneurons connected in an excitatory manner are essential for spontaneous episodes to occur (Fig. 11; top). When a sufficient number of motoneurons were retrogradely activated, a local episode of activity was triggered. Motoneuron axon collaterals that contact other motoneurons have been observed in adult cat cord (Cullheim et al., 1977), and we observed motoneuron axon collaterals terminating in multiple branches within the lateral motor column, which at E12 is almost exclusively composed of motoneuron somas. We also observed these collaterals terminating outside the lateral motor column in regions known to contain interneurons, some of which are GABAergic (Pierani et al., 2001). In fact, the GABAergic interneurons in the local circuit we have characterized might correspond to some of the V1 engrailedpositive population of interneurons, whose axons project short distances rostrally within the ventrolateral funiculus before terminating in the lateral motor column (Saueressig et al., 1999). In Xenopus tadpoles, cholinergic transmission between motoneurons has been demonstrated (Perrins and Roberts 1995a), most likely from motoneurons that excite interneurons (Perrins and Roberts, 1995b). Both contribute to the fidelity of the CPG that 
drives swimming. Based on ChAT expression, a small number of cholinergic interneurons have been identified in E14 rat cord (Phelps et al., 1990). However, we have not observed any ChAT- or VCATpositive neurons that could be unambiguously identified as interneurons in E12 mouse cord. Thus, we believe that all of the cholinergic inputs that contribute to the E12 mouse CGP most likely arise from motoneurons.

To propagate throughout the cord and elicit an episode of spontaneous activity, local circuit bursts require glycinergic interneurons

The existence of a separate, glycinergic interneuron-containing pathway (Fig. 11, middle) for the propagation of local episodes is supported by the failure of local episodes to propagate in the presence of strychnine. In addition, the cholinergic antagonists that blocked local episodes differed from those that blocked propagation (pharmacological data summarized in Fig. 11 , bottom). The nicotinic receptors involved in the local episodes (on motoneurons and perhaps GABAergic interneurons) were $\mathrm{DH} \beta \mathrm{E}$-insensitive, whereas those presumably on the glycinergic interneurons were $\mathrm{DH} \beta \mathrm{E}$-sensitive. Furthermore, because direct cord stimulation simultaneously activates motoneurons and GABAergic neurons, and spontaneous activity still persisted in the presence of mecamylamine and $\mathrm{dTC}$, we cannot rule out that the glycinergic neurons also excite the local GABAergic population of neurons. Finally, the circuit for propagation exhibited strong circuit depression so that another propagating episode could not be generated for at least $1 \mathrm{~min}$ after a spontaneous episode, similar to what has been observed in the E10-E12 chick (Fedirchuk et al., 1999). In contrast, the local circuit did not exhibit such depression. The fact that local episodes were rarely observed spontaneously suggests that the depolarization of the local circuit usually reached threshold for propagation throughout the cord before triggering a local burst. Consistent with this idea, frequent local bursts were observed when propagation was blocked by either $\mathrm{DH} \beta \mathrm{E}$ or strychnine. The identity of the glycinergic interneurons is currently unknown, but they could be among either the ipsilaterally projecting CHX10and LIM3-positive population of interneurons (Saueressig et al., 1999) or the contralaterally projecting Evx1-positive population, both of which project over four or five segments before terminating in the lateral motor column.

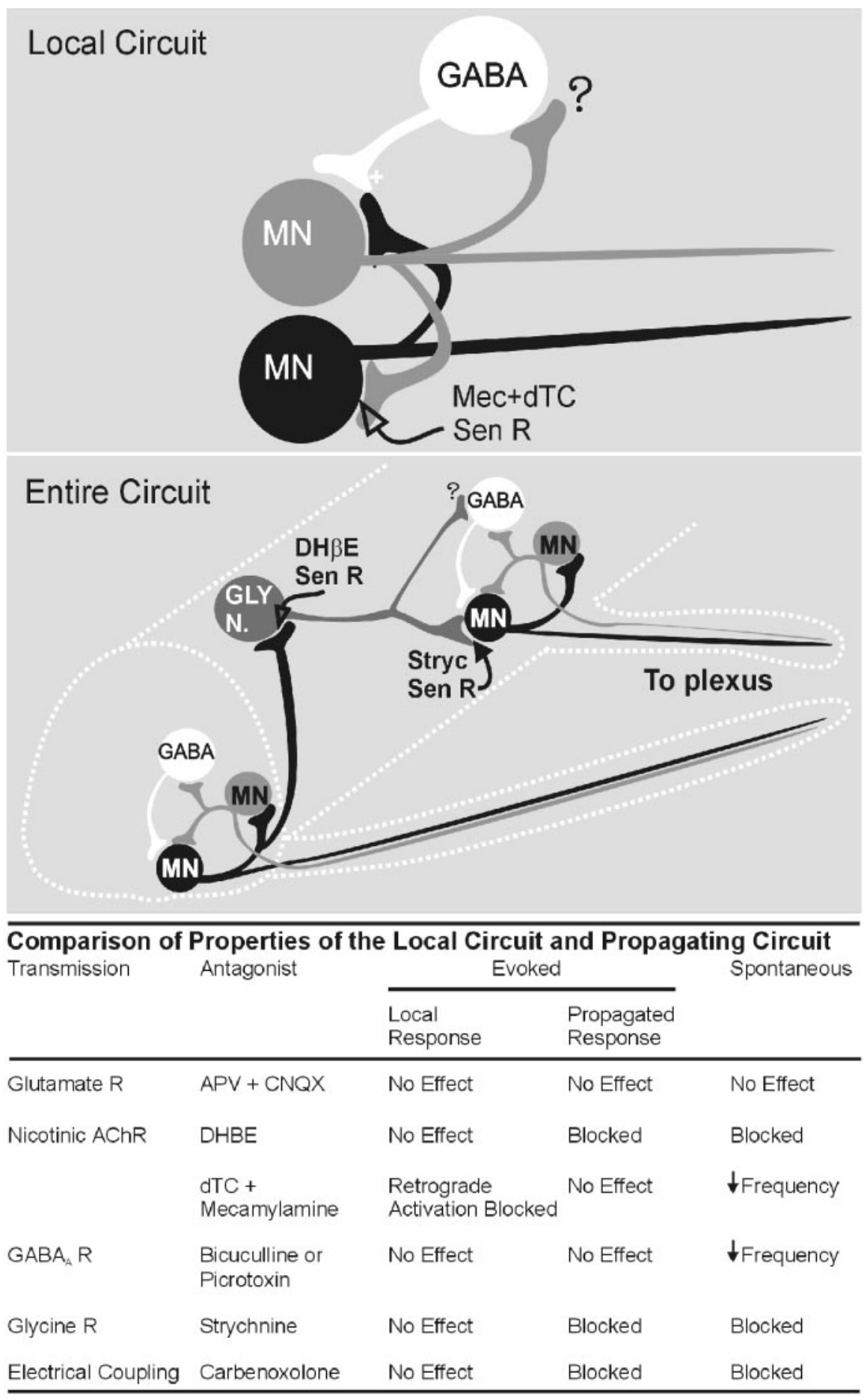

Figure 11. Proposed model of the E12 mouse spinal motor circuit. Top, The local circuit consists of two pathways for activation, GABAergic neurons that activate motoneurons and probably other GABAergic interneurons (not shown) and motoneurons, which activate other motoneurons and GABAergic interneurons via axon collaterals. Activation of either of these pathways by direct cord stimulus or by antidromic stimulation of motoneurons from the peripheral nerve results in a burst in the local circuit. Middle, Local episodes of activity propagate to other regions of the cord by motoneuron axon collaterals activating glycinergic interneurons. These subsequently activate local circuits at other segmental levels as well as contralaterally (not shown; see Discussion for additional detail). Bottom, Summary table comparing the properties of the local response, the propagating response, and the spontaneous episodes of activity for the E12 mouse spinal motor circuit. Note that cholinergic transmission in the local circuit is $\mathrm{DH} \beta \mathrm{E}$-insensitive, whereas that used in the propagating circuit and in spontaneously generated episodes is blocked by $\mathrm{DH} \beta \mathrm{E}$. Similarly, both the propagating circuit and spontaneous activity require electrical transmission, whereas the local circuit does not. MN, Motoneuron; Mec, mecamylamine; Sen R, sensitive receptor; Stryc, strychnine. 


\section{Involvement of gap junction coupling}

Electrical coupling via gap junctions is widespread in the developing nervous system, where it has been shown to play a role in competitive synapse elimination at the neuromuscular junction (Busetto et al., 2000; Personius and Balice-Gordon, 2001), the coordination of firing among both spinal interneurons (SaintAmant and Drapeau, 2001) and spinal motoneurons (Perrins and Roberts, 1995a,b), and the propagation of waves of action potentials in the retina (Catsicas et al., 1998; Wong et al., 1998; Singer et al., 2001). The CPG responsible for the earliest motor output in the zebrafish spinal cord appears to be coordinated primarily by electrical transmission (Saint-Amant and Drapeau, 2000). Furthermore in neonatal rat cord, after blockade of action potentials and chemical transmission, stable motor rhythms were generated by the synchronization of motoneuron oscillations across gap junctions (Tresch and Kiehn, 2000).

What role then does electrical coupling play in the generation of the earliest rhythmic activity in mouse cord? Electrical coupling has been demonstrated between motoneurons in neonatal rat cord, and the expression of gap junction proteins is high in the early embryonic rat lateral motor column (Chang et al., 1999). Thus, it was surprising that pharmacological blockade of gap junctions had no effect on the generation of local bursts via antidromic motoneuron activation; these appeared to be mediated solely by chemical transmission. However, blocking gap junctions did abolish spontaneous rhythmic activity, the ability to activate the lumbar cord by descending inputs, and the propagation of local episodes throughout the cord. This suggests that the network of glycinergic interneurons, whose activation is required for all three events, may be gap junction-coupled or need gap junctions for full activation. However, given that gap junction blockers used may have other nonspecific effects, direct demonstration of such coupling in early mouse cord circuits is needed.

In conclusion, we have characterized the circuits responsible for the earliest rhythmic motor activity in the mouse spinal cord and have demonstrated the existence of both local circuits and a circuit for synchronizing the local circuits throughout the cord. This should allow us to interfere with specific aspects of motor circuit activity either pharmacologically in the chick (Usiak and Landmesser, 1999) or genetically in the mouse (Saueressig et al., 1999) and to determine the subsequent effects on circuit formation and maturation both centrally and peripherally.

\section{References}

Barber RP, Phelps PE, Vaughn JE (1991) Generation patterns of immunocytochemically identified cholinergic neurons at autonomic levels of the rat spinal cord. J Comp Neurol 311:509-519.

Boehm S, Harvey RJ, von Holst A, Rohrer H, Betz H (1997) Glycine receptors in cultured chick sympathetic neurons are excitatory and trigger neurotransmitter release. J Physiol (Lond) 504:683-694.

Branchereau P, Morin D, Bonnot A, Ballion B, Chapron J, Viala D (2000) Development of lumbar rhythmic networks: from embryonic to neonate locomotor-like patterns in the mouse. Brain Res Bull 53:711-718.

Branchereau P, Chapron J, Meyrand P (2002) Descending 5-hydroxytryptamine raphe inputs repress the expression of serotonergic neurons and slow the maturation of inhibitory systems in mouse embryonic spinal cord. J Neurosci 22:2598-2606.

Busetto G, Buffelli M, Tognana E, Bellico F, Cangiano A (2000) Hebbian mechanisms revealed by electrical stimulation at developing rat neuromuscular junctions. J Neurosci 20:685-695.

Catsicas M, Bonness V, Becker D, Mobbs P (1998) Spontaneous $\mathrm{Ca}^{2+}$ transients and their transmission in the developing chick retina. Curr Biol 8:283-286.

Cazalets JR, Borde M, Clarac F (1995) Localization and organization of the central pattern generator in the newborn rat. J Neurosci 15:4943-4951.

Chang Q, Gonzalez M, Pinter MJ, Balice-Gordon RJ (1999) Gap junctional coupling and patterns of connexin expression among neonatal rat lumbar spinal motor neurons. J Neurosci 19:10813-10828.

Chen G, Trombley PQ, van den Pol AN (1996) Excitatory actions of GABA in developing rat hypothalamic neurones. J Physiol (Lond) 494:451-464.

Chub N, O’Donovan MJ (1998) Blockade and recovery of spontaneous rhythmic activity after application of neurotransmitter antagonists to spinal networks of the chick embryo. J Neurosci 18:294-306.

Chub N, O'Donovan MJ (2001) Post-episode depression of GABAergic transmission in spinal neurons of the chick embryo. J Neurophysiol 85:2166-2176.

Cullheim S, Kellerth JO, Conradi S (1977) Evidence for direct synaptic interconnections between cat spinal alpha-motoneurons via the recurrent axon collaterals: a morphological study using intracellular injection of horseradish peroxidase. Brain Res 132:1-10.

Draguhn A, Traub RD, Schmitz A, Jefferys JGR (1998) Electrical coupling underlies high-frequency oscillations in the hippocampus in vitro. Nature 394:189-192.

Dwoskin LP, Crooks PA (2001) Competitive neuronal nicotinic receptor antagonists: a new direction for drug discovery. J Pharmacol Exp Ther 298:395-402.

Elliot AA, Elliot JR (1989) The role of inactivation in the effects of n-alkanols on the sodium current of cultured rat sensory neurones. J Physiol (Lond) 415:19-33.

Fedirchuk B, Wenner P, Whelan PJ, Ho S, Tabak J, O’Donovan MJ (1999) Spontaneous network activity transiently depresses synaptic transmission in the embryonic chick spinal cord. J Neurosci 19:2102-2112.

Feller MB (1999) Spontaneous correlated activity in developing neural circuits. Neuron 22:653-656.

Feller MB, Wellis DP, Stellwagen D, Werblin FS, Shatz CJ (1996) Requirement for cholinergic synaptic transmission in the propagation of spontaneous retinal waves. Science 272:1182-1187.

Feller MB, Butts DA, Aaron HL, Rokhsar DS, Shatz CJ (1997) Dynamic processes shape spatiotemporal properties of retinal waves. Neuron 19:293-306.

Ganguly K, Schindler AF, Wang ST, Poo M-M (2001) GABA itself promotes the developmental switch of neuronal GABAergic responses from excitation to inhibition. Cell 105:521-532.

Garaschuk O, Hanse E, Konnerth A (1998) Developmental profile and synaptic origin of early network oscillations in the CA1 region of rat neonatal hippocampus. J Physiol (Lond) 507:219-236.

Hamburger V, Balaban M, Oppenheim R, Wenger E (1965) Periodic motility of normal and spinal chick embryos between 8 and 17 days of incubation. J Exp Zoo 159:1-13.

Hubner CA, Stein V, Hermans-Borgmeyer I, Meyer T, Ballanyi K, Jentsch TJ (2001) Disruption of KCC2 reveals an essential role of K-Cl cotransport already in early synaptic inhibition. Neuron 30:515-524.

Jiang ZG, Shen E, Wang MY, Dun NJ (1991) Excitatory postsynaptic potentials evoked by ventral root stimulation in neonate rat motoneurons in vitro. J Neurophysiol 65:57-66.

Jones CL (1979) The morphogenesis of the thigh of the mouse with special reference to tetrapod muscle homologies. J Morphol 162:275-309.

Kandler K, Katz LC (1998) Relationship between dye coupling and spontaneous activity in developing ferret visual cortex. Dev Neurosci 20:59-64.

Katz LC, Shatz CJ (1996) Synaptic activity and the construction of cortical circuits. Science 274:1133-1138.

Kjaeruluff O, Kiehn O (1996) Distribution of networks generating and coordinating locomotor activity in the neonatal rat spinal cord in vitro: a lesion study. J Neurosci 16:5777-5794.

Kulik A, Nishimaru H, Ballanyi K (2000) Role of bicarbonate and chloride in GABA- and glycine-induced depolarization and $\left[\mathrm{Ca}^{2+}\right]_{\mathrm{i}}$ rise in fetal rat motoneurons in situ. J Neurosci 20:7905-7913.

Lagerback PA, Ronnevi LO, Cullheim S, Kellerth JO (1981) An ultrastructural study of the synaptic contacts of alpha-motoneurone axon collaterals. I. Contacts in lamina IX and with identified alpha-motoneurone dendrites in lamina VII. Brain Res 207:247-266.

Landmesser LT, O’Donovan MJ (1984) Activation patterns of embryonic chick hind limb muscles recorded in ovo and in an isolated spinal cord preparation. J Physiol (Lond) 347:189-204.

Levi S, Chesnoy-Marchais D, Sieghart W, Triller A (1999) Synaptic control of glycine and GABA(A) receptors and gephyrin expression in cultured motoneurons. J Neurosci 19:7434-7449.

Lu J, Karadsheh M, Delpire E (1999) Developmental regulation of the 
neuronal-specific isoform of $\mathrm{K}-\mathrm{Cl}$ cotransporter $\mathrm{KCC} 2$ in postnatal rat brains. J Neurobiol 39:558-568.

Marshall DC, Buccafusco JJ (1987) Spinal cholinergic neurons and the expression of morphine withdrawal symptoms in the rat. J Neurosci 7:621-628.

Matsubayashi H, Alkondon M, Pereira EF, Swanson KL, Albuquerque EX (1998) Strychnine: a potent competitive antagonist of alphabungarotoxin-sensitive nicotinic acetylcholine receptors in rat hippocampal neurons. J Pharmacol Exp Ther 284:904-913.

Meister M, Wong RO, Baylor DA, Shatz CJ (1991) Synchronous bursts of action potentials in ganglion cells of the developing mammalian retina. Science 252:939-943.

Milner LD, Landmesser LT (1999) Cholinergic and GABAergic inputs drive patterned spontaneous motoneuron activity before target contact. J Neurosci 19:3007-3022.

Nishimaru H, Iizuka M, Ozaki S, Kudo N (1996) Spontaneous motoneuronal activity mediated by glycine and GABA in the spinal cord of rat fetuses in vitro. J Physiol (Lond) 497:131-143.

Nolan MF, Logan SD, Spanswick D (1999) Electrophysiological properties of electrical synapses between rat sympathetic preganglionic neurones in vitro. J Physiol (Lond) 519:753-764.

O’Donovan MJ (1999) The origin of spontaneous activity in developing networks of the vertebrate nervous system. Curr Opin Neurosci 9:94-104.

O’Donovan MJ, Landmesser L (1987) The development of hindlimb motor activity studied in the isolated spinal cord of the chick embryo. J Neurosci 7:3256-3264.

O’Donovan MJ, Wenner P, Chub N, Tabak J, Rinzel J (1998) Mechanisms of spontaneous activity in the developing spinal cord and their relevance to locomotion. Ann NY Acad Sci 860:130-141.

Owens DF, Boyce LH, Davis MB, Kriegstein AR (1996) Excitatory GABA responses in embryonic and neonatal cortical slices demonstrated by gramicidin perforated-patch recordings and calcium imaging. J Neurosci 16:6414-6423.

Ozaki S, Snider WD (1997) Initial trajectories of sensory axons toward laminar targets in the developing mouse spinal cord. J Comp Neurol 380:215-229.

Payne JA (1997) Functional characterization of the neuronal-specific $\mathrm{K}-\mathrm{Cl}$ cotransporter: implications for $\left[\mathrm{K}^{+}\right]_{\mathrm{o}}$ regulation. Am J Physiol 273:C1516-C1525.

Penn AA, Riquelme PA, Feller MB, Shatz CJ (1998) Competition in retinogeniculate patterning driven by spontaneous activity. Science 279:2108-2112.

Perrins R, Roberts A (1995a) Cholinergic and electrical motoneuron-tomotoneuron synapses contribute to on-cycle excitation during swimming in Xenopus embryos. J Neurophysiol 73:1005-1012.

Perrins R, Roberts A (1995b) Cholinergic contribution to excitation in a spinal locomotor central pattern generator in Xenopus embryos. J Neurophysiol 73:1013-1019.

Personius KE, Balice-Gordon RJ (2001) Loss of correlated motor neuron activity during synaptic competition at developing neuromuscular synapses. Neuron 31:395-408.

Phelps PE, Barber RP, Brennan LA, Maines VM, Salvaterra PM, Vaughn JE (1990) Embryonic development of four different subsets of cholinergic neurons in rat cervical spinal cord. J Comp Neurol 291:9-26.

Pierani A, Moran-Rivard L, Sunshine MJ, Littman DR, Goulding M, Jessell TM (2001) Control of interneuron fate in the developing spinal cord of the progenitor homeodomain protein Dbxl. Neuron 29:367-384.

Prior C, Marshall IG, Parsons SM (1992) The pharmacology of vesamicol: an inhibitor of the vesicular acetylcholine transporter. Gen Pharmacol 23:1017-1022.

Ramon y Cajal S (1952a) Substance grise et cellules motrices. In: Histologie du système nerveux de l'homme et des vertébrés (Azovlay L, ed), pp 353-370. Madrid: Consejo Superior De Investigaciones Cientificas.

Ramon y Cajal S (1952b) Histogénèse de la moelle et des ganglions rachidiens. In: Histologie du système nerveux de l'homme et des vertébrés (Azovlay L, ed), pp 601-611. Madrid: Consejo Superior De Investigaciones Cientificas.

Reichling DB, Kyrozis A, Wang J, MacDermott AB (1994) Mechanisms of
GABA and glycine depolarization-induced calcium transients in rat dorsal horn neurons. J Physiol (Lond) 476:411-421.

Rekling JC, Funk GD, Bayliss DA, Dong XW, Feldman JL (2000) Synaptic control of motoneuronal excitability. Physiol Rev 80:767-852.

Ritter A, Wenner P, Ho S, Whelan PJ, O’Donovan MJ (1999) Activity patterns and synaptic organization of ventrally located interneurons in the embryonic chick spinal cord. J Neurosci 19:3457-3471.

Roerig B, Feller MB (2000) Neurotransmitters and gap junctions in developing neural circuits. Brain Res Brain Res Rev 32:86-114.

Saint-Amant L, Drapeau P (2000) Motoneuron activity patterns related to the earliest behavior of the zebrafish embryo. J Neurosci 20:3964-3972.

Saint-Amant L, Drapeau P (2001) Synchronization of an embryonic network of identified spinal interneurons solely by electrical coupling. Neuron 31:1035-1046.

Saueressig H, Burill J, Goulding M (1999) Engrailed-1 and netrin-1 regulate axon pathfinding by association interneurons that project to motor neurons, Development 126:4201-4212.

Sernagor E, Chub N, Ritter A, O’Donovan MJ (1995) Pharmacological characterization of the rhythmic synaptic drive onto lumbosacral motoneurons in the chick embryo spinal cord. J Neurosci 15:7452-7464.

Sernagor E, Eglen SJ, O’Donovan MJ (2000) Differential effects of acetylcholine and glutamate blockade on the spatiotemporal dynamics of retinal waves. J Neurosci 20:RC56(1-6).

Shatz CJ (1996) Emergence of order in visual system development. Proc Natl Acad Sci USA 93:602-608.

Singer JH, Mirotznik RR, Feller MB (2001) Potentiation of L-type calcium channels reveals nonsynaptic mechanisms that correlate spontaneous activity in the developing mammalian retina. J Neurosci 21:8514-8522.

Stellwagen D, Shatz CJ (2002) An instructive role for retinal waves in the development of retinogeniculate connectivity. Neuron 33:357-367.

Tresch MC, Kiehn O (2000) Motor coordination without action potentials in the mammalian spinal cord. Nat Neurosci 3:593-599.

Usiak MF, Landmesser LT (1999) Neuromuscular activity blockade induced by muscimol and d-tubocurarine differentially affects the survival of embryonic chick motoneurons. J Neurosci 19:7925-7939.

Weliky M, Katz LC (1999) Correlational structure of spontaneous neuronal activity in the developing lateral geniculate nucleus in vivo. Science 285:599-604.

Wenner P, O'Donovan MJ (1999) Identification of an interneuronal population that mediates recurrent inhibition of motoneurons in the developing chick spinal cord. J Neurosci 19:7557-7567.

Wenner P, O'Donovan MJ (2001) Mechanisms that initiate spontaneous network activity in the developing chick spinal cord. J Neurophysiol 86:1481-1498.

Whelan P, Bonnot A, O’Donovan MJ (2000) Properties of rhythmic activity generated by the isolated spinal cord of the neonatal mouse. J Neurophysiol 84:2821-2833.

Wetts R, Vaughn JE (2001) Development of cholinergic terminals around rat spinal motor neurons and their potential relationship to developmental cell death. J Comp Neurol 435:171-183.

Wong RO (1999) Retinal waves and visual system development. Annu Rev Neurosci 22:29-47.

Wong RO, Meister M, Shatz CJ (1993) Transient period of correlated bursting activity during development of the mammalian retina. Neuron 11:923-938.

Wong RO, Chernjavsky A, Smith SJ, Shatz CJ (1995) Early functional neural networks in the developing retina. Nature 374:716-718.

Wong WT, Sanes JR, Wong RO (1998) Developmentally regulated spontaneous activity in the embryonic chick retina. J Neurosci 18:8839-8852.

Wu WL, Ziskind-Conhaim L, Sweet MA (1992) Early development of glycine- and GABA-mediated synapses in rat spinal cord. J Neurosci 12:3935-3945.

Zhou ZJ (1998) Direct participation of starburst amacrine cells in spontaneous rhythmic activities in the developing mammalian retina. J Neurosci 18:4155-4165.

Zhou ZJ, Zhao D (2000) Coordinated transitions in neurotransmitter systems for the initiation and propagation of spontaneous retinal waves. J Neurosci 20:6570-6577. 